\title{
Understanding Consumer Resistance to the Consumption of Organic Food. A Study of Ethical Consumption, Purchasing, and Choice Behaviour
}

\author{
Kushwah, Shiksha
}

2019-10

Kushwah , S , Dhir , A \& Sagar , M 2019 , ' Understanding Consumer Resistance to the Consumption of Organic Food. A Study of Ethical Consumption, Purchasing, and Choice Behaviour ' , Food Quality and Preference , vol. 77 , pp. 1-14 . https://doi.org/10.1016/j.foodqual.2019.04.003

http://hdl.handle.net/10138/313963

https://doi.org/10.1016/j.foodqual.2019.04.003

cc_by_nc_nd

acceptedVersion

Downloaded from Helda, University of Helsinki institutional repository.

This is an electronic reprint of the original article.

This reprint may differ from the original in pagination and typographic detail.

Please cite the original version. 


\section{Accepted Manuscript}

Understanding Consumer Resistance to the Consumption of Organic Food. A

Study of Ethical Consumption, Purchasing, and Choice Behaviour

Shiksha Kushwah, Amandeep Dhir, Mahim Sagar

PII:

S0950-3293(18)30981-9

DOI:

https://doi.org/10.1016/j.foodqual.2019.04.003

Reference:

FQAP 3691

To appear in:

Food Quality and Preference

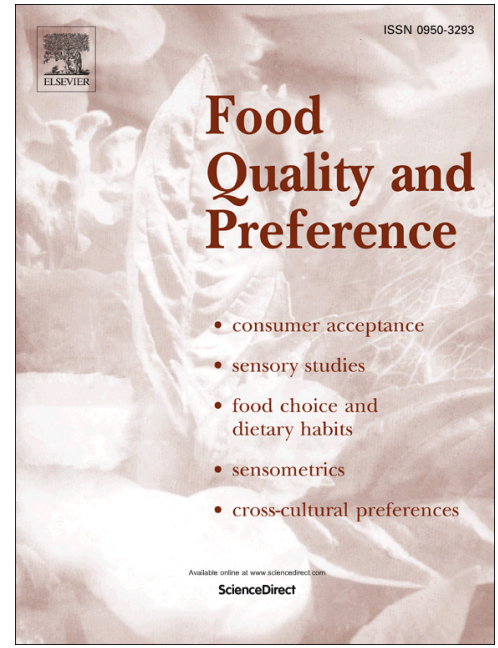

Received Date: 5 December 2018

Revised Date: $\quad 12$ March 2019

Accepted Date: $\quad 9$ April 2019

Please cite this article as: Kushwah, S., Dhir, A., Sagar, M., Understanding Consumer Resistance to the Consumption of Organic Food. A Study of Ethical Consumption, Purchasing, and Choice Behaviour, Food Quality and Preference (2019), doi: https://doi.org/10.1016/j.foodqual.2019.04.003

This is a PDF file of an unedited manuscript that has been accepted for publication. As a service to our customers we are providing this early version of the manuscript. The manuscript will undergo copyediting, typesetting, and review of the resulting proof before it is published in its final form. Please note that during the production process errors may be discovered which could affect the content, and all legal disclaimers that apply to the journal pertain. 
Understanding Consumer Resistance to the Consumption of Organic Food. A Study of Ethical Consumption, Purchasing, and Choice Behaviour

\section{Shiksha Kushwah}

Department of Management Studies, Indian Institute of Technology Delhi, India

*Email: shiksha.kushwah@gmail.com

\section{Dr. Amandeep Dhir}

Faculty of Educational Science, University of Helsinki, Finland

Optentia Research Focus Area, North-West University, Vanderbijlpark, South Africa

Email:amandeep.dhir@helsinki.fi

\section{Prof. Mahim Sagar}

Department of Management Studies, Indian Institute of Technology Delhi, India

Email: mahim@dms.iitd.ac.in

*Corresponding author

${ }^{5}$ Average variance extracted, ${ }^{6}$ Average shared squared variance, ${ }^{7}$ Maximum shared squared variance 


\title{
Understanding Consumer Resistance to the Consumption of Organic Food. A Study of Ethical Consumption, Purchasing, and Choice Behaviour
}

\author{
Abstract \\ Although the demand for organic food is growing globally, the mainstream consumption of organic food is \\ far less. The present study attempts to understand underlying reasons for consumer resistance toward \\ consuming organic food using the theoretical framework of innovation resistance theory (IRT). The study \\ further examines the association between different consumer barriers and purchase decisions (purchase \\ intentions, ethical consumption intentions, and choice behaviour) at different levels of buying involvement \\ and environmental concerns. The collected data, consisting of 452 consumers, were analyzed by structural \\ equation modeling approach. The results showed that value is the major barrier influencing purchase \\ intentions and ethical consumption intentions. Ethical consumption and purchase intention were found to \\ have direct influence on choice behaviour. Additionally, the relationship between ethical consumption \\ intention and choice behaviour is mediated by purchase intention. However, no significant differences have \\ emerged based on level of buying involvement and environment concerns. The findings of the study \\ provide insight into public policymakers, marketers, suppliers, and consumer associations by enhancing \\ their current understanding of buying behaviour of the growing organic food community. \\ Keywords. Consumer resistance, organic food, barriers, innovation resistance theory (IRT), \\ sustainable consumption
}




\section{Introduction}

During last few decades, the ethical consumerism has grown both in terms of scale and scope (Bennett, 2018; Hasanzade, Osburg, \& Toporowski, 2018; Ryan \& Casidy, 2018). Ethical consumerism is defined as the consumer activism focusing on the production and consumption of products based on social and environmental concerns (Bennett, 2018; Carrigan, Szmigin, \& Wright, 2004; Deschamps, Carnie, \& Mao, 2017; Harrison, Newholm, \& Shaw, 2005; Langen, 2011; O’Connor, Sims, \& White, 2017; Uusitalo \& Oksanen, 2004). These consumer activism movements connected a group of consumers making a decision based on similar ethical thinking (Long \& Murray, 2013). For instance, one such consumption community around organic food has become evident worldwide due growing consumerism movements in agro-food industry (Essoussi \& Zahaf, 2008; Szmigin, Maddock, \& Carrigan, 2006). This is attributed to the growing evidence of pesticides and chemicals in fresh as well as processed food products, rising health and environment concerns, expanding the urban population, increased spending on food production, and food quality issues (ASSOCHAM \& E\&Y, 2018; Essoussi $\&$ Zahaf, 2008). The consumers of this community are highly motivated, informed, and demanding with respect to the product's biological quality (Batalha \& Buainain, 2007). Consequently, the practice of organic farming and supply of organic food increased to fulfil the needs and demand of this growing community (Chekima, Oswald, Wafa, \& Chekima, 2017). This argument is further strengthened by the recent report on organic food scenario (Willer \& Lernoud, 2018). The report suggests that organic farming is now practiced in 178 countries with an increased in global sales from US\$7.9 billion in 2000 to US\$89.7 billion in 2016 (Willer \& Lernoud, 2018). Whilst, this exponential increased in global sales has stimulated the increase in total area under organic management globally. The number has reached 57.8 million hectare in 2016 from 11 million hectare in 1999. Furthermore, the wild collection and other non-agricultural areas has also increased from 11 million in 1999 to approximately 40 Million hectares 
in 2016. The leading countries with highest value of harvest area (wild) under organic management are Finland, Zambia and India with the values of 11.6 million hectares, 6.7 million hectares and 4.2 million hectares respectively (Willer \& Lernoud, 2018).

India is ranked at third position in terms of wild harvest area under organic management. India also ranked $1^{\text {st }}$ in terms of organic producers $(835,000)$ globally and occupies $9^{\text {th }}$ position in terms of area under organic cultivation (1.49 million hectare) (Willer \& Lernoud, 2018). Furthermore, India is currently exporting 300 organic products in 20 different categories in 20 different countries (APEDA, 2018). This reflects India's significant position in terms of organic production. During 2017-18, India has exported 4.58 lakh MT organic products valuing 515.44 Million USD (APEDA, 2018). However, contrary to India's significant position in terms of organic production and export, the domestic market of organic food product is at nascent stage of development with a per capita consumption of organic food product is at Euro 0.1 and thus contributes towards less than $1 \%$ of total market share (Willer \& Lernoud, 2018). Consequently, marketers, businesses and policy makers have developed several policies (“Operation Green, Rashtriya Krishi Vikas Yojana, Mission Organic Value Chain Development and Pradhan Mantri Kaushal Vikas Yojana"), compulsory certification (“Jaivik Bharat") and marketing initiatives (such as, farm to plate concept, ecommerce, domestic organic trade fares, farmers market) to promote domestic consumption of organic food (ASSOCHAM \& E\&Y, 2018) However, despite these above initiatives, the organic food marketers are still facing several challenges, due to which, organic food consumption in the home market is too low. According to a recent report, the organic food marketers in domestic market have incurred huge losses and even failed to achieve its targets and set goals (ASSOCHAM \& E\&Y, 2018). This clearly suggests the prevalence of significant consumer resistance or barriers toward the consumption of organic food among mainstream consumers. 
Consequently, suggesting an urgent and pertinent need to better study the consumer resistance to the consumption of organic food in India.

The present study broadly examine the underlying consumer resistances in organic food context. The three main aims of this proposed study are: a) to develop insights on the reasons of consumer resistance/barrier for purchasing organic food product. This will enable scholars to further develop newer insights for improving the growth of domestic organic food market; b) to examine the empirical linkages between consumer resistance or barriers, ethical consumption and purchase intentions, and ethical choice behavior; c) to analyze whether the consumer barriers of purchasing organic food varies among different studied consumer segments. The consumers were segmented based on purchasing involvement (buyer and non-buyer) and level of environmental concern (high, low and medium). Buyers are those who are actively involved in the buying of organic food product however, non-buyers are those who are not engaged in organic food buying. The current study has utilized a popular and well known theoretical framework of innovation resistance theory (IRT) since it provides a comprehensive understanding of the consumer resistance or barriers.

Two main significant contributions of this study are: First, almost all prior studies on organic food choice behavior focused on positive antecedents (motives) to choice behavior while the influence of negative antecedents (barriers) on choice behavior in organic food context was never studied. The current study is the first empirical study to provide a comprehensive view of these negative antecedents (consumer barriers) and their effect on intentions and choice behavior. Second, it examines the differences in intentions and choice behavior based on buying involvement and level of environmental concern, which is a distinctive contribution in studied context.

This study has significant practical implications for different stakeholders including practitioners, scholars, organic food farmers, consumers and policy makers. The study findings will 
enable different stakeholders to understand the foundations of consumer resistance or barriers towards the consumption of organic food. Furthermore, study results will enable them to better interpret the association of consumer barriers, intentions and choice behavior of consumers. Practitioners may utilize our findings to develop appropriate marketing and promotional strategies to reduce the stiff consumer resistance towards organic food.

\section{Background Literature}

\subsection{Organic food consumption}

Organic food, which used to be supply-driven, has now become demand-driven. Moreover, organic food has been re-launched as a "new product" under the green, eco, sustainable, or ethical products category (Thøgersen, 2010). In addition to this, organic food is also referred to as green innovation or ethical innovation in the academic literature (Thøgersen \& Zhou, 2012). Scholars argue that organic food provides ecological as well as social benefits along with added individual benefits (Cerjak et al., 2010).

Prior extended literature in the last decade has examined different issues in regard to organic food and consumers. This includes profiling of organic buyers (Chen, Lobo, \& Rajendran, 2014; Hansen et al., 2018; Nandi, Bokelmann, Gowdru, \& Dias, 2016; Petrescu, Petrescu-Mag, Burny, \& Azadi, 2017), motivations for buying organic food (Hansen et al., 2018; Hasselbach \& Roosen, 2015a; Hwang, 2016; Petrescu et al., 2017; Pham, Nguyen, Phan, \& Nguyen, 2018a; Scalvedi \& Saba, 2018; Sobhanifard, 2018), purchase intentions toward organic food (e.g., Asif, Xuhui, Nasiri, \& Ayyub, 2018; Çabuk, Tanrikulu, \& Gelibolu, 2014; Ham, Pap, \& Stanic, 2018; Hsu \& Chen, 2014; Lee \& Yun, 2015; Mainardes, de Araujo, Lasso, \& Andrade, 2017; Pham et al., 2018; Prakash, Singh, \& Yadav, 2018), willingness to pay (Hasselbach \& Roosen, 2015a; Lim, Yong, \& Suryadi, 2014) and consumer attitude toward consumption (Çabuk et al., 2014; Chekima et al., 2017; Janssen, 2018; Mainardes et al., 2017; Singh \& Verma, 2017; Teng \& Wang, 2015; Thøgersen, de Barcellos, Perin, \& Zhou, 2015b). 
The majority of prior empirical studies on organic food were carried out mainly in the United States ( Lee \& Goudeau, 2014; Rodman et al., 2014; Ryan \& Casidy 2018) and Europe (Janssen, 2018a; Janssen \& Hamm, 2014; Padilla Bravo, Cordts, Schulze, \& Spiller, 2013; Zagata, 2014). In comparison with this, a relatively fewer number of empirical studies were carried out in Asia, e.g., in China (Chen $e t$ al., 2014; Hasimu et al., 2017; Thøgersen et al., 2015b, 2016; Zhou et al., 2013), Iran (Asif et al., 2018; Sobhanifard, 2018), Jordon (Lillywhite, Al-Oun, \& Simonsen, 2013a), Pakistan (Asif et al., 2018), Vietnam (Pham et al., 2018), Malaysia (Chekima et al., 2017; Lim et al., 2014), Thailand (Sriwaranun et al., 2015), Turkey (Çabuk et al., 2014), and Taiwan (Chang \& Chang, 2017; Hsu \& Chen, 2014; Teng \& Wang, 2015).

Only few empirical evidence on consumption of organic food exists in context to emerging markets in Asia such as in India (Khare \& Pandey, 2017; Misra \& Singh, 2016; Nandi et al., 2016; Prakash et al., 2018; Singh \& Verma, 2017; Yadav \& Pathak, 2016a). However, most of these studies focused on the positive antecedents of intention and choice behavior. This may be due to India's prominent position in world organic food market in terms of organic food production and exports (APEDA, 2018) but, on the contrary the domestic consumption is still low indicating the presence of certain resistance faced by consumers. However, there is a lack of research that covers the comprehensive view of the barriers faced by the consumers in the Indian context. Thus, the present investigation helps scholars as well as relevant stakeholders in understanding consumer resistance or barriers in organic food context.

\subsection{Ethical consumption intentions toward organic food}

Consumers are increasingly making consumption choices based on ethical values, societal norms, and environmental standards (Coelho, 2015; Ladhari \& Tchetgna, 2017). Such consumers are referred to as being ethically minded (Carrington, Neville, \& Whitwell, 2010). They feel responsible for the wider 
range of issues such as societal, environmental, child labor, pollution, human rights, and many other similar concerns (Carrington et al., 2010). Scholars argue that, through purchasing perceived ethical products (e.g., organic food, fair trade, green or ecological products, energy-efficient appliances, and eco-vehicles) and boycotting unethical products (e.g., products or companies associated with unethical issues such as products developed with child labor), consumers portray their morals and values (Bennett, 2018; Carrington et al., 2010; Ladhari \& Tchetgna, 2017).

Scholars have proposed different definitions for ethical consumption. To begin with, Crane (2004) argued that ethical consumption is a serious and conscious decision related to consumption choices, and it is motivated by one's morals and belief system. Uusitalo and Oksanen (2004) referred to ethical consumption as a combination of ethical and moral aspects of production and distribution of different goods. Scholars insist that ethical consumption is a comprehensive concept because it encompasses all kinds of consumption such as green consumption, sustainable, socially conscious, and similar types of consumption (Carrigan et al., 2004; Long \& Murray, 2013). In context to the present study, we conceptualized ethical consumption as an act of buying products that consider various ethical attributes (e.g., human, enyironment, animal, etc.) besides the essential product benefits based on individual moral beliefs and values. Thus, ethical consumption mainly involves the buying of perceived ethical products (e.g., organic or energy-efficient appliances) or supporting ethical practices (e.g., recycling, fair-trade) of the companies. Numerous scholars have attempted to study the relationship between ethics and organic food. However, to the best of our understanding there is scant literature which investigated the influence of barriers on ethical consumption intention in organic food context. The findings of this relationship will suggest the various stakeholders regarding the resistance towards ethical consumption intention faced by consumers considering organic food as a context. 


\subsection{Purchase intentions in context to organic food and choice behaviour}

Purchase intention refers to willing to attempt or execute a particular behaviour (Ajzen, 1991). Purchase intention is considered as the most significant predictor of actual buying behaviour (Fishbein \& Ajzen, 1975). Numerous attempts have been made in the recent years to understand purchase intention toward organic food as a means to suggest consumer purchase behavior (Anisimova, 2016; Asif et al., 2018; Chang \& Chang, 2017; Chen et al., 2014; Ham et al., 2018; Husic-Mehmedovic et al., 2017; Mainardes et al., 2017; Ryan \& Casidy, 2018; Teng \& Wang, 2015; Yazdanpanah \& Forouzani, 2015).

Prior literature suggests that different theoretical frameworks were utilized to measure purchase intentions (see Table 1). The theory of planned behaviour (TPB) was the most utilized theoretical framework. Other theoretical framework utilized in the prior literature are stimulus-organism-response (Lee \& Yun, 2015), Schwartz values scale (Mainardes et al., 2017), self-concept theory and means-end theory (Husic-Mehmedovic et al., 2017), food choice questionnaire (Escobar-López et al., 2017), and the environmental value-attitude-system model (Pandey \& Khare, 2015). While these studies attempted to examine the influence of psychographic, situational, and product-related factors on purchase intention toward organic food, only one empirical study, to the best of researchers understanding, studied the role of barriers on purchase intentions (Pham et al., 2018). However, no prior empirical research has examined the different functional and psychological barriers toward the consumption of organic food using IRT. The present study has bridged this gap.

Insert Table 1 here

\section{Research Model and Hypothesis Development}

Despite the several efforts of the marketers and government, organic food product is still niche in Indian market (Yadav \& Pathak, 2016b). Consumer resistance toward a new product can be referred as the resistance that a consumer demonstrates toward any innovation either due to his or her unwillingness 
to change from a satisfied position point or due to any conflict that might affect a consumer's structure of beliefs (Ram \& Sheth, 1989). Seminal work on consumer resistance suggest there are numerous issues that consumer encounter due to re-adaptation during the introduction phase of the innovative products/services (Ram, 1989). But, consumer become receptive to new innovation only after the elimination of these barriers (Ram, 1987). Majority to the prior literature has focused on the proinnovation bias, which implies any new product or services are better than the existing product and consumer always want to try newest available product (Laukkanen, 2016). On the contrary, there is a scant literature on consumer resistance towards organic food. Therefore the present study has adapted Innovation resistance theory (IRT) framework to comprehensively study the barriers faced by consumers toward usage intentions and organic food consumption behavior.

IRT is suitable for the present study due to several reasons. First, IRT has the proven ability to explain why consumers refuse to buy new product. Thus, IRT is the most appropriate framework to further investigate the research questions in this study i.e. why the mainstream consumption of organic food is still low in Indian market or why the mainstream consumers refuse to adopt green/ethical innovation (organic food). Second, IRT is the most proven and validated framework to study the barrier or consumer resistance. It has been tested widely in technological product literature such as Internet banking (Lian and Yen 2013), mobile banking (Chaouali and Souiden 2018), buying cars online (Molesworth \& Suortti, 2002), smart product and services (Juric \& Lindenmeier, 2018; Mani \& Chouk, 2018), social media (Chen and Kuo 2017; Lian and Yen 2013), and thus would be a reliable tool for adaptation in organic food context. Lastly, IRT comprehensively explains all the major sources of consumer resistance in the form of functional and psychological barriers. The barriers or consumer resistance toward any new product can consist of both functional and psychological elements (Ram \& Sheth, 1989). Consumers face functional barriers when they perceive significant changes due to the 
adoption of a new product, whereas psychological barriers arise due to conflict with consumers "prior belief” (Ram \& Sheth, 1989). These two components were further categorized into different barriers based on their impact on consumer desire for the adoption of the new product. IRT has proposed three functional barriers, i.e., usage, value, and risk barriers, and two psychological barriers, i.e., tradition and image (Ram \& Sheth, 1989). Our research model has examined the influence of five barriers on the purchase intentions and intentions to consume organic food (see Figure 1). The organic food literature from barrier perspective is scattered and no comprehensive framework has been used to investigate the barriers faced by the consumers. Thus, the current study examines the empirical validity of IRT to study the major barriers faced by consumers in organic food context.

\subsection{Usage barrier}

Insert Figure 1 here

Usage barrier arises when a new product is incongruent with existing user patterns, workflow, and habits, and it could be the main factor for the resistance of the new product (Ram \& Sheth, 1989). Consumers usually respond to the change that disturbs their equilibrium (Ram, 1989). Organic food is considered as a form of incremental innovation instead of radical innovation. However, it still evokes the changes in habit and consumer usage patterns. Previous studies in organic food context suggests that the limited availability of organic food product (Hasimu et al., 2017; Henryks, Cooksey, \& Wright, 2014; Lillywhite et al., 2013a; Petrescu et al., 2017; Pham et al., 2018) and the lack of product consistency (González et al. 2009; Nandi et al. 2017) in the organic category results in the change in existing personal equilibrium of the consumers. For example, organic food buying is inclined to be more discontinuous than conventional food, as consumers have more information and familiarity with traditional food products. Thus, based on the previous argument, we put forward the following hypothesis: 
H1. Usage barrier is negatively associated with choice behaviour (H1a), purchase intention (H1b), and ethical consumption intention (H1c).

\subsection{Value barriers}

Value barriers occur when a new product is compared with its alternative or precursor based on performance and monetary value, and the newer product is found to be lower on these parameters (Ram \& Sheth, 1989). A new product must provide better on performance-to-price ratio to change a customer's current behaviour (Ram \& Sheth, 1989). The value barrier could be lowered by a relative advantage, which is proposed by Rogers (1995) as the degree to which an innovation/ new product is considered superior than the pre-existing idea or product.

Value barriers arise due to the perceived value differences of a new product to its alternative. In previous studies, organic buyers emphasized that it is difficult to differentiate organic food from conventional food based on appearance, so consumers worry that they might be paying high for the name of the organic food (Lim et al., 2014). Consumers are also not fully informed about the benefits and the true value of organic food, due to which, they are not willing to pay the higher prices, which, in turn, act as a barrier against organic food consumption (Botonaki, Polymeros, Tsakiridou, \& Mattas, 2006; Chen et al., 2014; Misra \& Singh, 2016). We propose the following hypothesis:

H2. Value barrier is negatively related to choice behavior $(\mathrm{H} 2 \mathrm{a})$, purchase intention $(\mathrm{H} 2 \mathrm{~b})$, and ethical consumption intention $(\mathrm{H} 2 \mathrm{c})$.

\subsection{Risk barrier}

Risk barrier is dependent on the consumer perception of the risk in a new product. It is defined as the degree to which a risk is considered integral to an innovation/new product (Ram \& Sheth, 1989). There is a certain degree of uncertainty involved with every new product/innovation; thus, consumers typically postpone the consumption of a product until that uncertainty is settled (Molesworth \& Suortti, 2002). Risk 
barrier could be in different forms. It may be (a) physical, if it impacts the physical condition of an individual or his/her property; (b) economic, if the cost of innovation is perceived to be higher, and further investment will lead to wastage of existing resources; (c) functional, if a consumer questions the functionality of the product; and (d) social, if consumer fear for social group approval.

A new product is always associated with a certain degree of risk. Furthermore, the higher the degree of risk, the slower will be the acceptance of a new product (Ram \& Sheth, 1989). Prior literature and our qualitative study suggested that lack of trust among stakeholders such as farmers, specialty stores and brands (Hsu \& Chen, 2014; Nandi et al., 2017; Scalvedi \& Saba, 2018), and lack of trust on certification agencies of organic food (Botonaki et al., 2006; Brył, 2018; Lea \& Worsley, 2005; Pham et al., 2018) posits a higher risk for consumers. Thus, we hypothesize that

H3. Risk barrier is negatively related to choice behavior (H3a), purchase intention (H3b), and ethical consumption intention $(\mathrm{H} 3 \mathrm{c})$.

\subsection{Tradition barrier}

A tradition barrier arises when an innovation involves changes in established traditions and norms of society and consumers' social and family values (Ram \& Seth, 1989). Consumers have developed social norms and values and also have routines and habits; any changes to any of these would lead to resistance toward new products (Laukkanen, 2016). Tradition barrier is a type of psychological barrier that may occur due to the conflict between consumers' existing value and beliefs rather than actual adoption and related experience of the product (Ram \& Seth, 1989). Drawing on these arguments, a tradition barrier in organic food context includes satisfaction with the conventional product (Botonaki et al., 2006), shorter shelf life (Bryła, 2016; Lillywhite et al., 2013a), and appearance and olfactory cues (Henryks et al., 2014; Lillywhite et al., 2013a; Nandi et al., 2017; Padel \& Foster, 2005). Therefore, it may act as a barrier among consumers 
because the majority of them are accustomed to shop as per the existing tradition and societal norms. Thus, we propose

H4. Tradition barrier is negatively related to choice behavior $(\mathrm{H} 4 \mathrm{a})$, purchase intention $(\mathrm{H} 4 \mathrm{~b})$, and ethical consumption intention $(\mathrm{H} 4 \mathrm{c})$.

\subsection{Image barrier}

An image barrier arises when any negative association is found between new product/innovation and its existing product line, brand or country of association (Ram \& Sheth, 1989). Thus, image barriers arise when consumers link the image of a new product with its existing heritage (Molesworth \& Suortti, 2002).

A new product or innovation generally inherits specific characteristics from its origins. This may be the product category, brand name, or country of origin (Laukkanen et al. 2009). Thus, image barrier could affect the intention as well as usage behaviour toward a new product. In the organic food context, image barriers include perceived skepticism, i.e., doubt or mistrust against the available organic food in the market (Henryks et al., 2014; Hsu \& Chen, 2014; Misra \& Singh, 2016) . Thus, those who do not buy organic food have a negative image toward the natural claims of the producers, which, in turn, affect the intention as well as usage behaviour. The above arguments lead to the next hypothesis of the present study:

H5. Image barrier is negatively related to choice behavior (H5a), purchase intention (H5b), and ethical consumption intention (H5c).

\subsection{Buying involvement as moderator}

Previous studies indicated significant differences among consumer groups based on their involvement and purchase experiences toward organic food (Finch, 2005; Lee \& Hwang, 2016; Squires et al., 2001). Finch (2005) argued that a set of consumption values differs among buyers and nonbuyers of organic food. Squires et al. (2001) explained that heavy organic food users have a negative attitude toward the food 
industry and a more positive attitude toward the environment and health and diet than light organic food users. In a recent study, Lee and Hwang (2016) also emphasized the significant difference between light and heavy users of organic food based on the relative importance of credence attributes of organic food. The authors further emphasized that negative influence of price on perceived value is higher in the case of the light user, while it is insignificant in the case of the heavy user. Consequently, it is likely that organic food buyers and nonbuyers differ from each other in terms of different consumer barriers. This is mainly because consumer barriers may vary among the different consumer groups based on their personal experiences and involvement. Furthermore, buyers and nonbuyers might also differ in purchase intentions, ethical consumption intentions, and organic food choice behavior. This study suggest the following hypothesis:

H6. The influence of different barriers on choice behaviour (H6a, H6b, H6c), purchase intention (H6d, H6e, H6f), and ethical consumption intention (H6g, H6h, H6i) is moderated by level of buying involvement

\subsection{Environmental concern as moderator}

Environmental concern is defined as the extent of consumer awareness about the environment and effort to support or willingness to contribute toward the implementation of solutions (Dunlap \& Jones, 2002, p.482). Prior literature suggested a significant influence of environmental concern on consumer purchase decisions (see Bryła, 2016; Hansen et al., 2018; Janssen, 2018; Smith \& Paladino, 2010; Yadav \& Pathak, 2016b). Thus, consumers with a higher environmental concern are expected to go for environmentalfriendly products such as organic food. Organic food is more environmentally friendly in comparison to the existing conventional alternatives (Essoussi \& Zahaf, 2008), as it is devoid of artificial ingredients such as chemicals, fertilizers, pesticides, and growth hormones (Çabuk et al., 2014). Furthermore, a previous study by Lin and Huang (2012) suggested that higher environmental concern leads to higher 
preference and choice of green products. Consequently, it is likely that environmental concerns may increase the inclination of consumers toward organic food consumption. Furthermore, environmental concerns can possibly lower the impact of different consumer barriers toward organic food. This study examined the moderating influence of environmental concerns on the relationship of different consumption barriers, purchase intention, ethical consumption intention, and choice behaviour. Thus, H7. Influence of different barriers on choice behaviour (H7a, H7b, and H7c), purchase intention (H7d, H7e, $\mathrm{H7f}$ ) and ethical consumption intention (H7g, H7h, H7i) is moderated by environmental concern

\section{Method}

\subsection{Data collection and study participants}

The research method of the present study includes all the seven steps suggested by Saunders, Lewis, and Thornhill (2016). This study is based on pragmatic paradigm. Ontologically, pragmatic view supports the multi-faceted nature of reality, which is generated externally. Thus, the research method is considered to be best when it appropriately answered the stated research question (Wahyni, 2012). Further, the pragmatic paradigm supports the integration of both inductive and deductive approach in a study (Creswell, 2007). Thus, this resonates with the stated aim of the present study.

The measures of the present study were adopted based on a comprehensive literature review and the result of qualitative research conducted on community-based organic food buyers. The semi structured interviews were utilized, as they have a proven ability in helping one to understand and generate context-specific factors (Bryman \& Emma, 2015). To get a broader perspective from determined consumers, we approached community-centric organic farmers markets. These markets are held on a weekly basis in particular community settings. They include both certified and noncertified organic food products. Further, because it involves direct interaction between consumer and farmers, trust plays a crucial role in this community (Szmigin et al., 2006). This characteristic distinguishes these community- 
centric organic farmers market from the supermarkets and specialty stores. Anonymous interviews were conducted to minimize any social desirability bias on the responses. To bring variability, different interview locations (organic farmers market) have been selected such as Sushant lok (Gurgaon), Chanakyapuri (Delhi), Asiad Village (Delhi), Vasant Kunj (Delhi), and Sector-15 (Noida). The interviews were conducted until the time theoretical saturation had been completed, and no new results have been revealed. Thus, a total 34 interviews were conducted. The qualitative data were analyzed using content analysis. A combination of deductive and inductive approaches has been used to derive the factors from data. This qualitative study helped to identify the additional facets of the study measures and to adapt them as per selected product category.

The questionnaire developed based on IRT was updated based on the qualitative data (see Table 2). A pre-testing of the questionnaire was carried with the sample of 45 online organic food community buyers. A few minor changes in order to bring more clarity and comprehensiveness were made. The questionnaire consisted of three main aspects: demographic variables, questions on experience and involvement with the organic food purchase, and, finally, items on consumer resistance toward organic food.

A total 452 people (buyers and nonbuyers of organic food) participated in the study (see Table 2). The face-to-face survey questionnaire answering sessions were conducted in community-based organic farmers markets (June to August 2018). Questionnaire survey has wide usage in organic food consumption literature (Chen, 2007; Fotopoulos \& Krystallis, 2002), as it provides more control to the researcher (Saunders et al., 2016). Further, the questionnaire survey also provides "quantifiability and objectiveness" to the study (Ackroyd and Hughes, 1981). For these reasons, questionnaire survey has been adopted for data collection. A qualifiers question has been used to differentiate buyers from 
nonbuyers. Five-point scales anchored between strongly disagree and strongly agree were used to access different study measures.

Insert Table 2 here

\subsection{Data analysis}

A two-step strategy of structural equation modeling (SEM) was utilized for data analysis (Anderson \& Gerbing, 1988). Statistical programs SPSS 23 and AMOS 23 were utilized. First, a confirmatory factor analysis (CFA) was performed to access the model fit indices and different forms of measurement validity and reliability. Second, the SEM was done to test the validity of the different stated research hypotheses. This is followed by the moderation analysis.

\section{Results}

\subsection{Measurement model}

The CFA of the measurement model returned a good model fit: $X^{2} / d f=2.06 ; T L I=0.96 ; C F I=0.97$; RMSEA $=0.05$ (Hair, Black, Babin, \& Anderson, 2010). Further, the factor loadings of all the measures in the studied context were above 0.60 , except for one item in the risk barrier $(0.45)$, which also exceeds the conventional cut-off (0.40) suggested by Hair et al. (2010) (see Table 3).

\section{Insert Table 3 here}

\subsection{Reliability and validity}

The different forms of reliability and validity analysis were performed with regard to the studied measures. The reliability analysis was undertaken using composite reliability (CR) to examine internal consistency of the measures under investigations. The CR value of all the study measures was found to be equal to or greater than the value of 0.70 , thus, consistent with the suggested threshold limit (Hair et al., 2010) (see Table 4). The study measures possess sufficient discriminant validity because the $\mathrm{AVE}^{5}$ 
is found to be greater than both the values of the $\mathrm{ASV}^{6}$ and $\mathrm{MSV}^{7}$ for the study measures (Fornell \& Larcker, 1981) (see Table 4). Similarly, study results confirmed that study measures possess sufficient convergent validity since $\mathrm{CR}$ was greater than equal to 0.70 , AVE was above 0.50 , and standardized factor loadings were above 0.50 (except one item for risk barrier) (Hair et al., 2010). It is noteworthy to mention that, because the two constructs of the study (i.e., tradition barrier and usage barrier) have come out with low factor loadings and also do not stand on the criteria of validity and reliability, we found this inconsistent with protocol suggested by (Hair et al., 2010) for measuring the structural model. Therefore, based on existing theoretical and methodological suggestions (Farrell, 2010; Hair et al., 2010), both of these measures were not considered at later stages of the investigation. Although extant literature suggested the significant role of tradition (Brył, 2018; Henryks et al., 2014; Misra \& Singh, 2016) and usage barrier (Henryks et al., 2014; Nandi et al., 2017; Pham et al., 2018) on consumer purchase decisions; however, both measures did not find support in our context. The probable reason could be that organic agriculture is considered as the cultural part of Indian tradition. It used to be the way of life during ancient times, however, due in order to accumulate the need for the growing population, the agriculture practices have adopted scientific practices. Thus, organic food enjoys a favorable position in terms of traditional values. This could be reflected from the latest statistics that India ranked $1^{\text {st }}$ in terms of number of organic producers globally (Willer \& Lernoud, 2018). Similarly, introduction of an organic food conventional food market may have minimized the usage barrier for the studied sample. Consequently, the final research model includes image, value and risk barriers, purchase intention, ethical consumption, and choice behaviour.

Insert Table 4 here

\subsection{Structural model}


The SEM of the structural model indicated a good model fit: $X^{2} / d f=2.03 ; C F I=0.97 ; T L I=0.96$; $R M S E A=0.05$. The results pertaining to tested hypotheses are presented in Figure 2. Hypotheses H1a, $\mathrm{H} 1 \mathrm{~b}$, and H1c, which posited that image barrier has a negative association with choice behavior, purchase intention, and ethical consumption intention, were not supported. The association of image barrier with choice behavior $(\beta=.02, n . s$.$) , purchase intention (\beta=.10$, n.s. $)$ and ethical consumption intention $(\beta=.08$, n.s.) were nonsignificant. $\mathrm{H} 2 \mathrm{a}, \mathrm{H} 2 \mathrm{~b}$, and $\mathrm{H} 2 \mathrm{c}$ proposed a negative association with value barrier and different types of consumption behavior. Only $\mathrm{H} 2 \mathrm{~b}$ and $\mathrm{H} 2 \mathrm{c}$ were supported, while $\mathrm{H} 2 \mathrm{a}$ was rejected. The study findings suggest that value barrier has a negative association with purchase intention $(\beta=.55$; $<0.001)$ and ethical consumption intention $(\beta=.32 ;<0.001)$, but association was insignificant in the case of choice behavior $(\beta=.11$; n.s.). Next, the result rejected $\mathrm{H} 3 \mathrm{a}, \mathrm{H} 3 \mathrm{~b}$, and $\mathrm{H} 3 \mathrm{c}$, which posited that the risk barrier is negatively associated with choice behavior $(\beta=-.06 ; n . s$.$) , purchase intention (\beta=-.09 ;$ n.s. $)$, and ethical consumption intention $(\beta=.09 ;$ n.s. $)$. Last, $\mathrm{H} 4, \mathrm{H} 5$, and $\mathrm{H} 6$ were supported, as ethical consumption intentions were positively associated with purchase intention $(\beta=.23 ;<0.001)$, purchase intentions had a positive association with ethical choice behavior $(\beta=.35 ;<0.001)$, and ethical consumption intentions had positive association with on choice behavior $(\beta=.22 ;<0.001)$, respectively (see Table 3 and Figure 2 ).

Insert Figure 2 here

\subsection{Moderation analysis}

The analysis also involved examining the moderating influence of buying behavior and environmental concern on the different study measures. The analysis was executed using PROCESS macro in SPSS. The study findings suggest that buying behavior and environmental concern did not have any moderating influence in the majority of the investigated relationships (see Table $7 \& 9$ ). In the case of buying behavior, it only moderated the association of value barrier with purchase intentions $(\beta=.16)$ and ethical consumption intention $(\beta=.19)$. Specifically, it was found that the buyers and nonbuyers of 
organic food differed significantly in terms of the influence of the value on intentions toward purchase and ethical consumption (see Table 8). On the other hand, environmental concern moderated the relationship between: (i) value barrier and purchase intentions $(\beta=.11)$, and (ii) image barrier and choice behavior $(\beta=.08)$. However, it should be noted that only value barrier exhibited statistically significant influence on purchase intentions for consumers having low, medium, and high concerns toward the environment (see Table 10). On the contrary, image barrier does not show any significantly different behavior in terms of choice behavior for users having low, medium, and high environmental concern.

Insert Table 5, 6, 7 and 8 here

\section{Discussion}

Most prior literature has focused on understanding the underlying motives behind the consumption of organic food. However, for obtaining holistic understanding of consumer behavior toward organic food, it is imperative to understand the barriers or underlying reasons for not buying organic food. Therefore, first, the present study aims to explore reasons for consumer resistance toward organic food in the Indian context using innovation resistance theory (IRT). Second, the relationship between identified barriers and three types of purchase decisions, namely, purchase, ethical consumption intentions and choice behavior has been empirically examined. Lastly, the moderating role of buying behavior (buyers and nonbuyers) and environment concern (low, medium, and high concerns toward environment) on organic food purchase decisions has been investigated.

The study results indicate that value barrier is the most significant and the only barrier against organic food consumption in the Indian context. Value barrier negatively influences both ethical consumption intentions and choice behaviour $(\mathrm{H} 2 \mathrm{~b}$ and $\mathrm{H} 2 \mathrm{c})$. Value barrier emerged when consumer evaluates the perceived value of the organic food in terms of its constituents and found the disparity on 
the same in comparison to conventional product. This finding is consistent with the recent studies in different cultural context. Torres-Ruiz, Vega-Zamora, and Parras-Rosa, 2018 in their study in Spain also reported lower value of organic food in comparison to conventional food as the significant barrier among the studied population. The possible explanation for these findings could be that the benefits associated with organic food in comparison with conventional alternatives are not very clear and profound among consumers; thus, it negatively influences the purchase decision. Misra and Singh (2016) suggested that doubt in regard to the professed quality of organic food hinders organic food consumption. On the contrary, this findings supports the existing literature which conclude that healthiness (Botonaki et al., 2006; Bryła, 2016; Cerjak et al., 2010; Hasimu et al., 2017; Henryks et al., 2014; Janssen, 2018a; Lea \& Worsley, 2005; Lillywhite et al., 2013a; Misra \& Singh, 2016; Nandi et al., 2016; Petrescu et al., 2017; Scalvedi \& Saba, 2018; Sobhanifard, 2018; Sondhi, 2014; Thøgersen et al., 2015b; Thøgersen \& Zhou, 2012; von Meyer-Höfer et al., 2015; Zagata, 2014), natural ingredients (Hasselbach \& Roosen, 2015a; Janssen, 2018b; Sobhanifard, 2018; Thøgersen \& Zhou, 2012; Zagata, 2014) and free from characteristics (González, 2009; Henryks et al.,2014; Nandi et al., 2017; Zagata, 2014) acts as the positive influencer for buying organic food.

Image barrier refers to the overall image of organic food among consumer groups. An image barrier may arise due to lack of clarity or confusion or growing skepticism toward the available organic food in the market. However, no support for associated hypothesis, namely, purchase intention (H1a), ethical consumption intention (H1b), and choice behaviour ( $\mathrm{H} 1 \mathrm{c})$, was found. Our finding is contrary to the findings of Padel and Foster (2005), which revealed that mistrust on available organic food in the super market as the reason for the attitude-behaviour gap. The possible explanation behind the inconsistent results could be that consumers are clear about the basic characteristics of the organic food 
products and the market is sufficiently developed. Consequently, consumers are able to make conscious choice to buy or not to buy organic food.

The influence of risk barriers on purchase intention (H3a), ethical consumption intention (H3b), and choice behaviour $(\mathrm{H} 3 \mathrm{c})$ were nonsignificant. Risk barrier mainly arises due to perception rather than functional attribute. These perceptions may be toward stakeholders involved in the supply chain as well as certification agencies. The findings are contrary to the existing literature that indicated lack of trust of stakeholders (Chen et al., 2014; Scalvedi \& Saba, 2018) and certification agencies (Pham et al., 2018; Sondhi, 2014) as the constraint impeding organic food consumption. The possible reasoning explaining inconsistent results could be that introduction of alternative buying possibilities such as farmers markets, community-supported agriculture, and grow your own food networks. In context to present study, the consumer directly interacts with all the stakeholders, and this results in more information exchange, strong relationships, and, consequently, more trust between buyer and producer. Further, it exponentially reduces the risk barriers.

The study findings confirm significant association between purchase intentions and choice behaviour, consistent with previous literature (Ham et al., 2018; von Meyer-Höfer et al., 2015). The other major insight of the study is that ethical consumption intentions are also significantly associated with purchase intentions as well as the choice behaviour. The study findings suggest that consumers with higher ethical consumption intentions are likely to possess high purchase intentions and favorable choice behavior toward an organic food purchase. The possible reasoning could be the presence of credence attributes in organic food products (Janssen \& Hamm, 2012; Massey, O’Cass, \& Otahal, 2018), which, in turn, bring it into the purview of ethical consumerism.

The findings of the moderation analysis indicate that purchasing behavior (buyer versus nonbuyers) has no influence on the majority of associations. It has only moderated the association among 
value barrier and purchase intentions and ethical consumption intentions. It is noteworthy to mention that value barrier is the only barrier that influences organic food buyers as well as nonbuyers. The findings are contrary to existing literature, which suggests significant differences between different segments of consumers (Finch, 2005; Lee \& Hwang, 2016). The possible reason behind differences in the findings could be the context of the study. Organic used to be a way of life for Indian consumers, and it is imbibed in Indian culture. Therefore, nonbuyers consider that whatever they are consuming comes from farmers and is hence already organic. These nonbuyers did not find any significant differences in the attributes of organic food product compared with the conventional products, and, thus, choose not to buy due to high prices. This could be inferred from qualitative excerpts as well.

Interviewer: What do you understand by organic food? And what stops you from buying organic food? Participant 1 (nonbuyer, 35, male): “...for me organic food is what coming from farmers... There is lot of misuse and abuse of term organic today ... people must realize that it is a fad ... these are just priced high to be sold to the rich people”.

Participant 2 (nonbuyer, 45, female): “...While the intellectual class wants to have pure, healthy, and hygienic food but always promotes *organic* and pushes biological additives like pesticides, fertilizer, hormones, insecticides, enzymes, and so on. Organic is not natural. Organic in the market is just replacing every chemical intervention in the *natural* process of plant growth, with biological intervention."

The other possible explanation could be nonbuyers' confidence in conventional food products, which may be because they believe that it is the government and policymaker's imperative to decide the limits of agriculture inputs to be used in farming. Consequently, the government should be taking care of it and may implement a ban when it is needed. The findings also suggest that, similar to nonbuyers, 
buyers may also believe that organic food choices and prices are the two major constraints faced by them. This observation is consistent to the results of the qualitative study. Participant (buyer, 35, male): "Organic is chemical free, pesticides free and healthy food. It is recommended by my colleagues and my family doctor, too ... sometime cost of the product act as a hindrance to me."

Last, the result of the study indicates that environmental concerns moderate the relationship between value barrier and purchase intentions and image barrier and choice behavior. However, only value barrier exhibited a statistically significant association on purchase intentions for consumers having low, medium, and high concerns toward the environment. Thus, it supports the existing findings by Lin and Huang (2012), which suggest that consumers with higher environmental concern are likely to have higher preferences for green products. The possible explanation could be that consumers define the value of the organic food based on various characteristics such as chemical free, pesticides free, and hormone free, and these attributes are certainly related to the environment welfare as well. Thus, consumers who are concerned about the value of the organic food may also be more sensitive toward the environment. Contrary to value barrier, image and risk barriers do not show any significantly difference in the choice for user having low, medium, and high environmental concern. This may be because environmental concern is mainly related to functional attributes of the products, and, on the other hand, risk and image barriers are mainly perceptual and thus may not influence the purchase decision process. To the end, these findings have various implications to different stakeholders, which is discussed in the next section.

\section{Study Implications}

The findings of this study have several implications to both theory and practice. 


\subsection{Theoretical implications}

The current study significantly contributes to the emerging literature on organic food consumption in various ways. First, the current study has significantly extended the scope of ongoing empirical investigations on organic food consumption related behaviour. This is the first empirical study that has examined the different consumer barriers or resistance towards organic food consumption and their association with intentions and choice behavior. In addition to this, currently study has extended the theoretical foundations of the prior literature by utilizing a never used theoretical framework of innovation resistance theory (IRT) in context to organic food consumption. Although this theory has been adapted into multiple domains but possibly present study is the first research study that utilised IRT in organic food context.

Second, the current study makes a valuable input to the existing literature on purchase related decision making in context to organic food by exploring both behavioural intentions (in the form of purchase and ethical consumption intentions) and choice behaviour of organic food consumption community. Thus, this is in coherence with the most recent literature that has also advocated the need to focus on actual choice behaviour along with behavioural intentions because behavioural intentions alone may not represent actual purchase behaviour (Ham et al., 2018; Prakash et al., 2018; Yadav \& Pathak, 2016b). In addition to this, current study has also tested the measures related to ethical consumption intentions along with the purchase intentions due to altruistic values associated with the organic food product.

Third, present study improves the existing insights in reference to consumer barriers faced by different consumer segments. Organic food consumption has been studied on nondifferentiated consumer segments, but comparisons between consumer segments based on their involvement and level of environmental concern in organic food purchase decision-making is rarely investigated. Only 
two exceptions are so far acknowledged (Finch, 2005; Lee \& Hwang, 2016). However, these studied on differentiated segments were not pertaining to resistance or consumer barriers faced by the consumers in the studied context. This study significantly contributes new understanding on consumer barriers faced by different consumer segments based on their buying involvement (buyers and nonbuyers) and environmental concerns (high, medium, and low).

\subsection{Practical implications}

The study findings are valuable for different stakeholders. This includes scholars, practitioners, farmers, marketers, policymakers, and even firms interested in the organic food industry. First, the study results showed value barrier as the most significant barrier in the studied context. This indicates that consumers perceive that organic food does not considerable value or it does not offer significant advantage over the conventional food products available in the market. In this respect, marketers could design a marketing campaign focusing on the benefits of the organic food consumption in comparison to conventional alternatives available in the markets. Furthermore, marketers could illustrates health benefits of organic food products comparison to conventional products to mitigate the resistance faced by them due to perceived lower value of the product.

Second, findings of this research study also suggests that value barrier influences the buying decisions of both buyers and non-buyers. This indicates that buyers were able to make price and value tradeoff at certain instances and thus leads to buying of organic food. But, this also reflect their concerns for perceived lower value and this may be influencing their purchase decisions in certain other categories. However, in case of nonbuyers, this is significantly hinder their purchase decisions. Marketers can utilize these findings for designing communication programs for buyers as well as nonbuyers. Drawing on regulatory focus theory (Higgins, 1998), a promotion focused message could be designed for non-buyers to improve their knowledge pertaining to the benefits of organic food, and a 
prevention focus message could be targeted at users to strengthen their existing belief regarding the benefits of adopting organic food. Further, the message for buyers could focus on various aspects that leads to higher value in terms of health, nutrition and free from characteristics (such as chemical, fertilizers and insecticides) of organic food, particularly the one that reflect the organic standard, to strengthen their belief about the value of the organic food product comparison to conventional alternative.

Third, the study results suggest that value barrier has significant association with ethical consumption intention. This is an important findings for marketers as well as public policy makers working towards promotion of ethical products (such as organic food) under the purview of green, sustainable or ethical consumption. The findings indicates that consumers are not satisfied with the value of the ethically positioned products. Thus, these products does not stand on the dimension of expected customer perceived value. Hence, public policy initiatives should focus on the policies and initiatives which could improve the perception of the consumer regarding the perceived value of the organic food product. Further, marketers could use these ethical attributes (farmers welfare, environment welfare) to provide consumer grounding for higher product value while promoting the product under the under the purview of ethical consumption.

Fourth, study results suggest the absence of image and risk barriers in the studied context. The findings indicates that the consumers' confusion as well as risk regarding organic food product has been minimized and thus, does not create consumer resistance. This may be due to some of the recent public policy initiatives taken by the government such as compulsory "Jaivik Bharat" certification from $1^{\text {st }}$ July 2019 on all the products being produced and sold under organic category. Along with this, government has also organized several national and international trade fairs for organic food products to mitigate the risk and image barrier among consumer by providing the platform for retailer, farmers and consumers to 
interact with each other's. Along these, government has taken several other initiatives also to strengthen the organic food industry (such as subsidies and strengthening of the community relationships).

Last, policymakers and government, who are working toward the strengthening of the ethical, green, or sustainable consumption practices, can target these growing consumption community around organic food, as the results indicated the strong relation between ethical consumption intention and choice behaviour. This may be due to the altruistic nature (environmental, animal, and farmer's welfare) of the organic food products. The other products and public services similar in line could be targeted to these community.

\section{Limitations and Future Work}

Although the current investigation has provided newer insight into the organic consumption community, our research study deals with few limitations, which could be considered in future research work. First, this study focused on a single community, i.e., organic consumption. Ethical consumption is a broad concept, similar to organic food, in that many other consumption communities could be studied such as fair-trade, recycling, green products, and similar. Thus, this model can be tested on other consumption communities around ethical causes. Second, consumers face numerous other barriers, and these are contextual. Future studies may include other barriers as well to broaden the scope of the studied subject area. Third, previous studies advocated to consider the well-established buyers and should focus on buying behaviour than their intentions. This will avoid literal inconsistencies and over-reporting of results. Considering this in mind, our organic buyer's sample mainly includes the consumers who were buying from the community-centric farmers market. However, this may influence their decision making due to the opinion of like-minded peers around them and the dynamics of the purchasing environment. Future research may have to maintain a trade-off between these biases through the environment and to bring more clarity in collected data. Fourth, as explained in Section 5.2, tradition and usage barriers have 
to be dropped in current study due to low factory loading and lack of appropriate validity and reliability;

in future research, different measures could be identified and tested for measuring these constructs. In addition to this, we encourage scholars to investigate the influential role of brand love, reputation, and trust with respect to organic food consumption related issues.

\section{References}

Aguirre González, J. A., Antonio, J., \& González, A. (2009). Market trends and consumer profile at the organic farmers market in Costa Rica. British Food Journal, 111(5), 145.

Ajzen, I. (1991). The theory of planned behavior. Organizational Behavior and Human Decision Processes, 50(2), 179-211.

Anisimova, T. (2016). Integrating Multiple Factors Affecting Consumer Behavior Toward Organic Foods: The Role of Healthism, Hedonism, and Trust in Consumer Purchase Intentions of Organic Foods. Journal of Food Products Marketing, 22(7), 809-823.

APEDA. (2018). Organic Products. Retrieved September 5, 2018, from http://apeda.gov.in/apedawebsite/organic/Organic_Products.htm

Arvola, A., Vassallo, M., Dean, M., Lampila, P., Saba, A., Lähteenmäki, L., \& Shepherd, R. (2008). Predicting intentions to purchase organic food: The role of affective and moral attitudes in the Theory of Planned Behaviour. Appetite, 50(2-3), 443-454.

Asif, M., Xuhui, W., Nasiri, A., \& Ayyub, S. (2018). Determinant factors influencing organic food purchase intention and the moderating role of awareness: A comparative analysis. Food Quality and Preference, 63(August 2017), 144-150.

ASSOCHAM, \& E\&Y. (2018). The Indian Organic Market A New Paradigm in Agriculture. Retrieved from https://www.ey.com/Publication/vwLUAssets/ey-the-indian-organicmarket-report-online-version-21-march-2018/\$File/ey-the-indian-organic-marketreport-online-version-21-march-2018.pdf

Bartels, J., \& van den Berg, I. (2011). Fresh fruit and vegetables and the added value of antioxidants; Attitudes of non-, light, and heavy organic food users. British Food Journal, 113(11), 1339-1352.

Batalha, M. O., Buainain, A. M. (2007). Cadeia Prdutiva da Carne Bovida. Série Agronegócios.

Bennett, E. A. (2018). Extending ethical consumerism theory to semi-legal sectors: insights from recreational cannabis. Agriculture and Human Values, 35(2), 295-317.

Botonaki, A., Polymeros, K., Tsakiridou, E., \& Mattas, K. (2006). The role of food quality certification on consumers' food choices. British Food Journal, 108(2), 77-90.

Brył, P. (2018). Organic food online shopping in Poland. British Food Journal, 120(5), 1015-1027. 
Bryła, P. (2016). Organic food consumption in Poland: Motives and barriers. Appetite, 105, 737-746.

Bryman, A., \& Emma, B. (2015). Business Research Methods. Oxford University Press, 2015. New: Oxford University Press.

Çabuk, S., Tanrikulu, C., \& Gelibolu, L. (2014). Understanding organic food consumption: Attitude as a mediator. International Journal of Consumer Studies, 38(4), 337-345.

Carrigan, M., Szmigin, I., \& Wright, J. (2004). Shopping for a Better world? An Anterpretive Study of the Potential for Ethical Consumption Within the Older Market. Journal of Consumer Marketing, 21(6), 401-417.

Carrington, M. J., Neville, B. A., \& Whitwell, G. J. (2010). Why ethical consumers don't walk their talk: Towards a framework for understanding the gap between the ethical purchase intentions and actual buying behaviour of ethically minded consumers. Journal of Business Ethics, 97(1), 139-158.

Cerjak, M., Mesić, Ž., Kopić, M., Kovačić, D., \& Markovina, J. (2010). What motivates consumers to buy organic food: Comparison of Croatia, Bosnia Herzegovina, and Slovenia. Journal of Food Products Marketing, 16(3), 278-292.

Chang, S. H., \& Chang, C. W. (2017). Tie strength, green expertise, and interpersonal influences on the purchase of organic food in an emerging market. British Food Journal, 119(2), 284-300.

Chaouali, W., \& Souiden, N. (2018). The role of cognitive age in explaining mobile banking resistance among elderly people. Journal of Retailing and Consumer Services.

Chekima, B., Oswald, A. I., Wafa, S. A. W. S. K., \& Chekima, K. (2017). Narrowing the gap: Factors driving organic food consumption. Journal of Cleaner Production, 166, $1438-1447$.

Chen, J., \& Lobo, A. (2012). Organic food products in China: determinants of consumers' purchase intentions. The International Review of Retail, Distribution and Consumer Research, 22(3), 293-314.

Chen, J., Lobo, A., \& Rajendran, N. (2014). Drivers of organic food purchase intentions in mainland China - evaluating potential customers' attitudes, demographics and segmentation. International Journal of Consumer Studies, 38(4), 346-356.

Chen, M.F. (2007). Consumer attitudes and purchase intentions in relation to organic foods in Taiwan: Moderating effects of food-related personality traits. Food Quality and Preference, 18(7), 1008-1021.

Chen, P. T., \& Kuo, S. C. (2017). Innovation resistance and strategic implications of enterprise social media websites in Taiwan through knowledge sharing perspective. Technological Forecasting and Social Change, 118, 55-69.

Coelho, S. L. (2015). Fair trade consumers in Portugal: Values and lifestyles. International Journal of Consumer Studies, 39(5), 437-444. 
Crane A, M. D. (2004). Business ethics: A European perspective. Business Ethics.

Creswell, J. W. (2007). Qualitative inquiry and research design: Choosing among five traditions. Sage Publication (2nd ed.). Thousand Oaks, CA: SAGE Publication.

Dean, M., Raats, M. M., \& Shepherd, R. (2012). The Role of Self-Identity, Past Behavior, and Their Interaction in Predicting Intention to Purchase Fresh and Processed Organic Food. Journal of Applied Social Psychology, 42(3), 669-688.

Deschamps, T. C., Carnie, B., \& Mao, N. (2017). Public consciousness and willingness to embrace ethical consumption of textile products in Mexico. Textiles and Clothing Sustainability, 2(1).

Dowd, K., \& Burke, K. J. (2013). The influence of ethical values and food choice motivations on intentions to purchase sustainably sourced foods. Appetite, 69, 137-144.

Dunlap, R. E., \& Jones, R. E. (2002). Environmental Concern: Conceptual and Measurement Issues. (R. E. Dunlap \& w Michelson, Eds.), Handbook of Environmental Sociology. London: Greenwood.

Ergönü, B., \& Ergönü, P. G. (2015). Consumer motivation for organic food consumption. Emirates Journal of Food and Agriculture, 27(5), 416-422.

Escobar-López, S. Y., Espinoza-Ortega, A., Vizcarra-Bordi, I., \& Thomé-Ortiz, H. (2017). The consumer of food products in organic markets of central Mexico. British Food Journal, 119(3), 558-574.

Essoussi, L. H., \& Zahaf, M. (2008). Decision making process of community organic food consumers : an exploratory study, 25(2), 95-104.

Farrell, A. M. (2010). Insufficient discriminant validity: A comment on Bove, Pervan, Beatty, and Shiu (2009). Journal of Business Research, 63(3), 324-327.

Finch, J. E. (2005). An Evaluation of Consumer Willingness to Pay for Organic Produce in the Northeastern U.S. Journal of Food Products Marketing, 11(4), 3-20.

First, I., \& Brozina, S. (2009). Cultural influences on motives for organic food consumption. EuroMed Journal of Business, 4(2), 185-199.

Fishbein, M., \& Ajzen, I. (1975). Belief, attitude, intention and behavior: an introduction to theory and research. An Introduction to Theory and Research. Addison- Wesley, Reading, MA.

Fornell, C., \& Larcker, D. F. (1981). Evaluating structural equation models with unobservable variables and measurement error. Journal. Journal of Marketing Research, 18(1), 39-50.

Fotopoulos, C., \& Krystallis, A. (2002). Purchasing motives and profile of the Greek organic consumer: a countrywide survey. British Food Journal, 104(9), 730-765.

González, J. A. A. (2009). Market trends and consumer profile at the organic farmers market in Costa Rica. British Food Journal, 111(5), 498-510. 
Hair, J., Black, W., Babin, B., \& Anderson, R. (2010). Multivariate Data Analysis a Global Perspective, Prentice Hall. Upper Saddle River, NJ (7th ed.). Prentice Hall.

Ham, M., Pap, A., \& Stanic, M. (2018). What drives organic food purchasing? - evidence from Croatia. British Food Journal, 120(4), 734-748.

Hamzaoui-Essoussi, L., \& Zahaf, M. (2012). Canadian Organic Food Consumers' Profile and Their Willingness to Pay Premium Prices. Journal of International Food and Agribusiness Marketing, 24(1), 1-21.

Hansen, T., Sørensen, M. I., \& Eriksen, M. L. R. (2018). How the interplay between consumer motivations and values influences organic food identity and behavior. Food Policy, 74(October 2017), 39-52.

Harrison, R., Newholm, T., \& Shaw, D. (2005). The ethical consumer. The Ethical Consumer.

Hasanzade, V., Osburg, V. S., \& Toporowski, W. (2018). Selecting decision-relevant ethical product attributes for grocery shopping. Management Decision, 56(3), 591-609.

Hasimu, H., Marchesini, S., \& Canavari, M. (2017). A concept mapping study on organic food consumers in Shanghai, China. Appetite, 108, 191-202.

Hasselbach, J. L., \& Roosen, J. (2015a). Consumer Heterogeneity in the Willingness to Pay for Local and Organic Food. Journal of Food Products Marketing, 21(6), 608-625.

Henryks, J., Cooksey, R., \& Wright, V. (2014). Organic Food at the Point of Purchase: Understanding Inconsistency in Consumer Choice Patterns. Journal of Food Products Marketing, 20(5), 452-475.

Higgins, E. T. (1998). Promotion and Prevention: Regulatory Focus as A Motivational Principle. Advances in Experimental Social Psychology, 30, 1-46.

Hsu, C. L., \& Chen, M. C. (2014). Explaining consumer attitudes and purchase intentions toward organic food: Contributions from regulatory fit and consumer characteristics. Food Quality and Preference, 35, 6-13.

Huh, E. J. (2011). Analysis of attitude and purchase intention regarding. Ethical Korean Journal of Consumer Studies, 22, 89-111.

Husic-Mehmedovic, M., Arslanagic-Kalajdzic, M., Kadic-Maglajlic, S., \& Vajnberger, Z. (2017). Live, Eat, Love: life equilibrium as a driver of organic food purchase. British Food Journal, 119(7), 1410-1422.

Hwang, J. (2016). Organic food as self-presentation: The role of psychological motivation in older consumers' purchase intention of organic food. Journal of Retailing and Consumer Services, 28, 281-287.

Janssen, M. (2018a). Determinants of organic food purchases: Evidence from household panel data. Food Quality and Preference, 68(February), 19-28.

Janssen, M. (2018b). Determinants of organic food purchases: Evidence from household panel data. Food Quality and Preference, 68(April 2017), 19-28. 
Janssen, M., \& Hamm, U. (2012). Product labelling in the market for organic food: Consumer preferences and willingness-to-pay for different organic certification logos. Food Quality and Preference, 25(1), 9-22.

Janssen, M., \& Hamm, U. (2014). Governmental and private certification labels for organic food: Consumer attitudes and preferences in Germany. Food Policy, 49(P2), 437-448.

Juric, J., \& Lindenmeier, J. (2018). An empirical analysis of consumer resistance to smartlighting products. Lighting Research \& Technology.

Khare, A., \& Pandey, S. (2017). Role of green self-identity and peer influence in fostering trust towards organic food retailers. International Journal of Retail and Distribution Management, 45(9), 969-990.

Konuk, F. A. (2018). Price fairness, satisfaction, and trust as antecedents of purchase intentions towards organic food. Journal of Consumer Behaviour, 17(2), 141-148.

Ladhari, R., \& Tchetgna, N. M. (2017). Values , socially conscious behaviour and consumption emotions as predictors of Canadians' intent to buy fair trade products. International Journal of Consumer Studies, 41(6), 696-705.

Langen, N. (2011). Are ethical consumption and charitable giving substitutes or not? Insights into consumers' coffee choice. Food Quality and Preference, 22(5), 412-421.

Laukkanen, P., Sinkkonen, S., \& Laukkanen, T. (2008). Consumer resistance to internet banking: postponers, opponents and rejectors. International Journal of Bank Marketing, 26(6), 440-455.

Laukkanen, T. (2016). Consumer adoption versus rejection decisions in seemingly similar service innovations: The case of the Internet and mobile banking. Journal of Business Research, 69(7), 2432-2439.

Laukkanen, T., Sinkkonen, S., Kivijärvi, M., \& Laukkanen, P. (2007). Innovation resistance among mature consumers. Journal of Consumer Marketing, 24(7), 419-427.

Laukkanen, T., Sinkkonen, S., \& Laukkanen, P. (2009). Communication strategies to overcome functional and psychological resistance to Internet banking. International Journal of Information Management, 29(2), 111-118.

Lea, E., \& Worsley, T. (2005). Australians' organic food beliefs, demographics and values. British Food Journal, 107(11), 855-869.

Lee, H.-J., \& Yun, Z.-S. (2015). Consumers perceptions of organic food attributes and cognitive and affective attitudes as determinants of their purchase intentions toward organic food. Food Quality and Preference, 39, 259-267.

Lee, H. J. (2016). Individual and Situational Determinants of U.S. Consumers' Buying Behavior of Organic Foods. Journal of International Food and Agribusiness Marketing, 28(2), 117-131.

Lee, H. J., \& Goudeau, C. (2014). Consumers' beliefs, attitudes, and loyalty in purchasing organic foods: The standard learning hierarchy approach. British Food Journal, 116(6), 
918-930.

Lee, H. J., \& Hwang, J. (2016). The driving role of consumers' perceived credence attributes in organic food purchase decisions: A comparison of two groups of consumers. Food Quality and Preference, 54, 141-151.

Lian, J. W., \& Yen, D. C. (2013). To buy or not to buy experience goods online: Perspective of innovation adoption barriers. Computers in Human Behavior, 29(3), 665-672.

Lillywhite, J. M., Al-Oun, M., \& Simonsen, J. E. (2013a). Examining Organic Food Purchases and Preferences Within Jordan. Journal of International Food and Agribusiness Marketing, 25(2), 103-121.

Lim, W. M., Yong, J. L. S., \& Suryadi, K. (2014). Consumers' Perceived Value and Willingness to Purchase Organic Food. Journal of Global Marketing, 27(5), 298-307.

Lin, P. C., \& Huang, Y. H. (2012). The influence factors on choice behavior regarding green products based on the theory of consumption values. Journal of Cleaner Production, 22(1), 11-18.

Lodorfos, G. N., \& Dennis, J. (2008). Consumers' intent: In the organic food market. Journal of Food Products Marketing, 14(2), 17-38.

Long, M. A., \& Murray, D. L. (2013). Ethical Consumption, Values Convergence/Divergence and Community Development. Journal of Agricultural and Environmental Ethics, 26(2), 351-375.

Mainardes, E. W., de Araujo, D. V. B., Lasso, S., \& Andrade, D. M. (2017). Influences on the intention to buy organic food in an emerging market. Marketing Intelligence and Planning, 35(7), 858-876.

Mani, Z., \& Chouk, I. (2018). Consumer Resistance to Innovation in Services: Challenges and Barriers in the Internet of Things Era*. Journal of Product Innovation Management, 35(5), 780-807.

Massey, M., O'Cass, A., \& Otahal, P. (2018). A meta-analytic study of the factors driving the purchase of organic food. Appetite, 125, 418-427.

Michaelidou, N., \& Hassan, L. M. (2008). The role of health consciousness, food safety concern and ethical identity on attitudes and intentions towards organic food. International Journal of Consumer Studies, 32(2), 163-170.

Michaelidou, N., \& Hassan, L. M. (2010). Modeling the factors affecting rural consumers' purchase of organic and free-range produce: A case study of consumers' from the Island of Arran in Scotland, UK. Food Policy, 35(2), 130-139.

Misra, R., \& Singh, D. (2016). An analysis of factors affecting growth of organic food: Perception of consumers in Delhi-NCR (India). British Food Journal, 118(9), 23082325.

Molesworth, M., \& Suortti, J.-P. (2002). Buying Cars Online: The Adoption of the Web for High-Involvement, High-Cost Purchases. Journal of Consumer Behaviour, 2(0), 154- 
169.

Nandi, R., Bokelmann, W., Gowdru, N. V., \& Dias, G. (2016). Consumer motives and purchase preferences for organic food products: Empirical evidence from a consumer survey in Bangalore, South India. Journal of International Food and Agribusiness Marketing, 28(1), 74-99.

Nandi, R., Bokelmann, W., Gowdru, N. V., \& Dias, G. (2017). Factors Influencing Consumers' Willingness to Pay for Organic Fruits and Vegetables: Empirical Evidence from a Consumer Survey in India. Journal of Food Products Marketing, 23(4), 430451.

O’Connor, E. L., Sims, L., \& White, K. M. (2017). Ethical food choices: Examining people's Fair Trade purchasing decisions. Food Quality and Preference, 60(October 2016), 105112.

Onyango, B. M., Hallman, W. K., \& Bellows, A. C. (2007). Purchasing organic food in US food systems: A study of attitudes and practice. British Food Journal, 109(5), 399-411.

Padel, S., \& Foster, C. (2005). Exploring the gap between attitudes and behaviour. British Food Journal (Vol. 107).

Padilla Bravo, C., Cordts, A., Schulze, B., \& Spiller, A. (2013). Assessing determinants of organic food consumption using data from the German National Nutrition Survey II. Food Quality and Preference, 28(1), 60-70.

Pandey, S. K., \& Khare, A. (2015). Decisional factors driving organic food consumption: Generation of consumer purchase intentions. Journal of Indian Business Research, 7(4), 1066.

Persaud, A., \& Schillo, S. R. (2017). Purchasing organic products: role of social context and consumer innovativeness. Marketing Intelligence \& Planning, 35(1), 130-146.

Petrescu, D. C., Petrescu-Mag, R. M., Burny, P., \& Azadi, H. (2017). A new wave in Romania: organic food. Consumers' motivations, perceptions, and habits. Agroecology and Sustainable Food Systems, 41(1), 46-75.

Pham, T. H., Nguyen, T. N., Phan, T. T. H., \& Nguyen, N. T. (2018). Evaluating the purchase behaviour of organic food by young consumers in an emerging market economy. Journal of Strategic Marketing, 4488, 1-17.

Pino, G., Peluso, A. M., \& Guido, G. (2012). Determinants of Regular and Occasional Consumers' Intentions to Buy Organic Food. Journal of Consumer Affairs, 46(1), 157169.

Prakash, G., Singh, P. K., \& Yadav, R. (2018). Application of consumer style inventory (CSI) to predict young Indian consumer's intention to purchase organic food products. Food Quality and Preference, 68(February), 90-97.

Ram, S. (1989). Successful innovation using strategies to reduce consumer resistance. An empirical test. The Journal of Product Innovation Management, 6(1), 20-34. 
Ram, S., \& Sheth, J. N. (1989). Consumer Resistance to Innovations: The Marketing Problem and its solutions. Journal of Consumer Marketing, 6(2), 5-14.

Roberts, J. A. (1996). Green Consumers in the 1990s: and Implications for Advertising. Journal of Business Research, 36(3), 217-231.

Rodman, S. O., Palmer, A. M., Zachary, D. A., Hopkins, L. C., \& Surkan, P. J. (2014). “They just say organic food is healthier": Perceptions of healthy food among supermarket shoppers in Southwest Baltimore. Culture, Agriculture, Food and Environment, 36(2), 83-92.

Rogers, E. M. (1995). Diffusion of Innovations. New York Free Press (4th Editio).

Ryan, J., \& Casidy, R. (2018). The role of brand reputation in organic food consumption: A behavioral reasoning perspective. Journal of Retailing and Consumer Services, 41(July 2017), 239-247.

Saunders, M., Lewis, P., \& Thornhill, A. (2016). Research Methods for Business Students. Pearson.

Scalvedi, M. L., \& Saba, A. (2018). Exploring local and organic food consumption in a holistic sustainability view. British Food Journal, 120(4), 749-762.

Shaharudin, M. R., Pani, J. J., Mansor, W. S., \& Elias, J. S. (2010). Factors Affecting Purchase Intention of Organic Food in Malaysia's Kedah State. Cross-Cultural Communication, 6(2), 105-116.

Shaw, D., \& Shiu, E. (2002). An assessment of ethical obligation and self-identity in ethical consumer decision-making: A structural equation modelling approach. International Journal of Consumer Studies, 26(4), 286-293.

Singh, A., \& Verma, P. (2017). Factors influencing Indian consumers' actual buying behaviour towards organic food products. Journal of Cleaner Production, 167, 473483.

Sirieix, L., Kledal,P. R., \& Sulitang, T. (2011). Organic food consumers' trade-offs between local or imported, conventional or organic products: A qualitative study in Shanghai. International Journal of Consumer Studies, 35(6), 670-678.

Smith, S., \& Paladino, A. (2010). Eating clean and green? Investigating consumer motivations towards the purchase of organic food. Australasian Marketing Journal, $18(2), 93-104$.

Sobhanifard, Y. (2018). Hybrid modelling of the consumption of organic foods in Iran using exploratory factor analysis and an artificial neural network. British Food Journal, 120(1), 44-58.

Sondhi, N. (2014). Assessing the organic potential of urban indian consumers. British Food Journal, 116(12), 1864-1878.

Squires, L., Juric, B., \& Cornwell, T. B. (2001). Level of market development and intensity of organic food consumption: Cross-cultural study of Danish and New Zealand 
consumers. Journal of Consumer Marketing, 18(4/5), 392-409.

Szmigin, I., Maddock, S., \& Carrigan, M. (2006). Conceptualising community consumption.

Teng, C.-C., \& Wang, Y.-M. (2015). Decisional factors driving organic food consumption. British Food Journal, 117(3), 1066-1081.

Teng, C. C., \& Lu, C. H. (2016). Organic food consumption in Taiwan: Motives, involvement, and purchase intention under the moderating role of uncertainty. Appetite, $105,95-105$.

Thøgersen, J. (2010). Country differences in sustainable consumption: The case of organic food. Journal of Macromarketing, 30(2), 171-185.

Thøgersen, J., de Barcellos, M. D., Perin, M. G., \& Zhou, Y. (2015a). Consumer buying motives and attitudes towards organic food in two emerging markets: China and Brazil. International Marketing Review, 32(3-4), 389-413.

Thøgersen, J., de Barcellos, M. D., Perin, M. G., \& Zhou, Y. (2015b). Consumer buying motives and attitudes towards organic food in two emerging markets. International Marketing Review, 32(3/4), 389-413.

Thøgersen, J., \& Zhou, Y. (2012). Chinese consumers' adoption of a 'green' innovation The case of organic food. Journal of Marketing Management, 28(3-4), 313-333.

Thøgersen, J., Zhou, Y., \& Huang, G. (2016). How stable is the value basis for organic food consumption in China? Journal of Cleaner Production, 134, 214-224.

Torres-Ruiz, F. J., Vega-Zamora, M., \& Parras-Rosa, M. (2018). False barriers in the purchase of organic foods. The case of extra virgin olive oil in Spain. Sustainability (Switzerland), 10(2), 1-14.

Uusitalo, O., \& Oksanen, R. (2004). Ethical consumerism: A view from Finland. International Journal of Consumer Studies, 28(3), 214-221.

Vega-Zamora, M., Torres-Ruiz, F. J., Murgado-Armenteros, E. M., \& Parras-Rosa, M. (2014). Organic as a heuristic cue: What Spanish consumers mean by organic foods. Psychology and Marketing.

von Meyer-Höfer, M., Olea-Jaik, E., Padilla-Bravo, C. A., \& Spiller, A. (2015). Mature and Emerging Organic Markets: Modelling Consumer Attitude and Behaviour With Partial Least Square Approach. Journal of Food Products Marketing, 21(6), 626-653.

Willer, H., \& Lernoud, J. (2018). The World of Organic Agriculture Statistics and Emerging Trends 2018. Retrieved from http://www.organic-world.net/yearbook/yearbook2018.html

Yadav, R. (2016). Altruistic or egoistic: Which value promotes organic food consumption among young consumers? A study in the context of a developing nation. Journal of Retailing and Consumer Services, 33, 92-97.

Yadav, R., \& Pathak, G. S. (2016a). Intention to purchase organic food among young consumers: Evidences from a developing nation. Appetite, 96, 122-128. 
Yadav, R., \& Pathak, G. S. (2016b). Intention to purchase organic food among young consumers: Evidences from a developing nation. Appetite, 96, 122-128.

Yadav, R., \& Pathak, G. S. (2016c). Young consumers' intention towards buying green products in a developing nation: Extending the theory of planned behavior. Journal of Cleaner Production, 135, 732-739.

Yazdanpanah, M., \& Forouzani, M. (2015). Application of the Theory of Planned Behaviour to predict Iranian students' intention to purchase organic food. Journal of Cleaner Production, 107, 342-352.

Zagata, L. (2012). Consumers' beliefs and behavioural intentions towards organic food. Evidence from the Czech Republic. Appetite, 59(1), 81-89.

Zagata, L. (2014). Towards conscientious food consumption: Exploring the values of Czech organic food consumers. International Journal of Consumer Studies, 38(3), 243-250.

Zhou, Y., Thøgersen, J., Ruan, Y., \& Huang, G. (2013). The moderating role of human values in planned behavior: The case of Chinese consumers' intention to buy organic food. Journal of Consumer Marketing, 30(4), 335-344. 
Figure 1. Our research model and proposed hypothesis

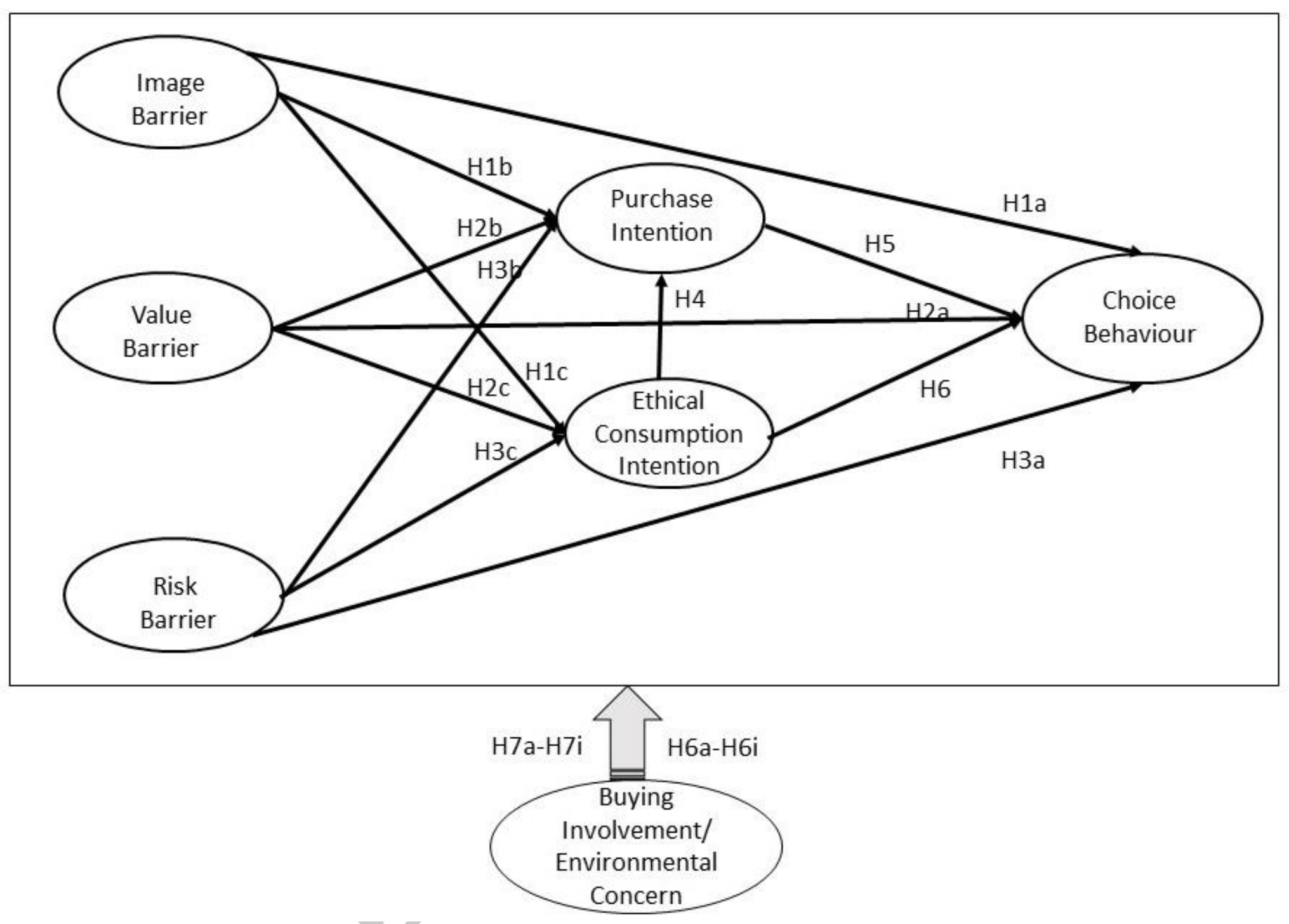




\section{Figure 2. Structural model}

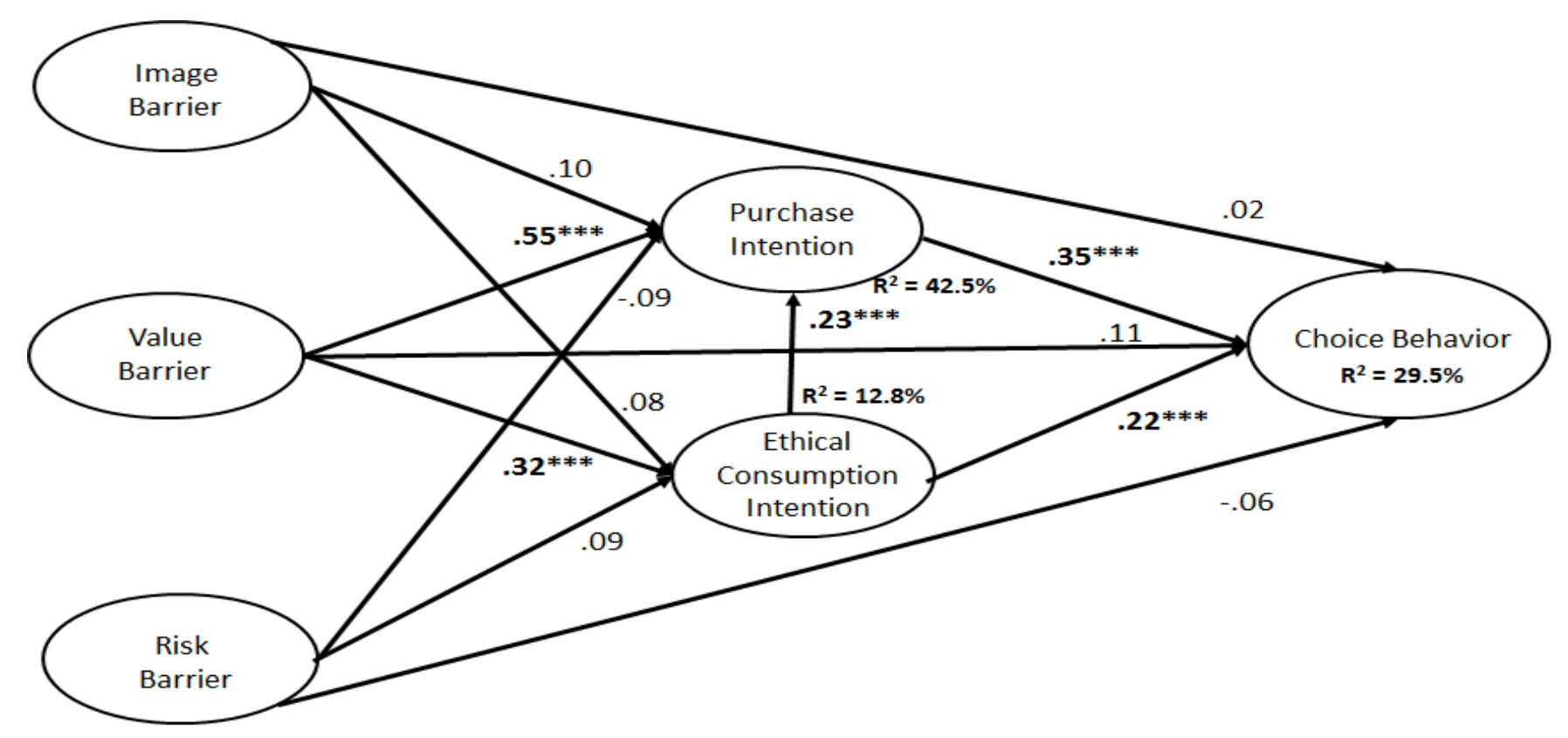


Table 1. Review of prior literature on purchase intentions towards organic food

\begin{tabular}{|c|c|c|c|c|c|}
\hline $\begin{array}{l}\text { Authors } \\
\text { (Year) }\end{array}$ & Theory & Study measures (Variables) & Sample* & Method & Study Focus \\
\hline $\begin{array}{l}\text { (Asif et al., } \\
\text { 2018) }\end{array}$ & ТPB & ATT, PBC, SN, awareness, HC, EC & $\begin{array}{l}\text { 730; NM; NM; } \\
\text { Pakistan, Turkey } \\
\text { \& Iran }\end{array}$ & SEM & $\begin{array}{l}\text { To study the significant factors } \\
\text { influencing purchase intention } \\
\text { in reference to organic food }\end{array}$ \\
\hline $\begin{array}{l}\text { (Prakash et al., } \\
\text { 2018) }\end{array}$ & $\begin{array}{l}\text { Consumer } \\
\text { Styles } \\
\text { Inventory } \\
\text { (CSI) }\end{array}$ & $\begin{array}{l}\text { High-quality consciousness, } \\
\text { Perfectionism, novelty consciousness, } \\
\text { brand consciousness, habitual/brand } \\
\text { loyal, confusion by over choice, HC, } \\
\text { hedonistic shopping consciousness, } \\
\text { recreational, impulsiveness, price } \\
\text { consciousness, } \\
\text { environmental consciousness }\end{array}$ & $\begin{array}{l}527 ; 18-28 ; 46 \% \\
\text { India }\end{array}$ & SEM & $\begin{array}{l}\text { To explore decision making of } \\
\text { consumer in organic food } \\
\text { context }\end{array}$ \\
\hline (Konuk, 2018) & NA & $\mathrm{HC}, \mathrm{EC}, \mathrm{CI}$ & $\begin{array}{l}274 ; 26-35 ; \\
\text { Pregnant women; } \\
\text { Turkey }\end{array}$ & SEM & $\begin{array}{l}\text { To study the effect of HC, EC } \\
\text { and customer innovativeness } \\
\text { on purchase intention of } \\
\text { pregnant women and WTP } \\
\text { towards organic food }\end{array}$ \\
\hline $\begin{array}{l}\text { (Pham et al., } \\
\text { 2018) }\end{array}$ & NA & $\begin{array}{l}\mathrm{EC} \text {, food safety concern, } \mathrm{HC} \text {, food } \\
\text { taste, media exposure, perceived } \\
\text { barriers }\end{array}$ & $\begin{array}{l}289 ; 18-21 ; \\
51.2 \% ; \text { Vietnam }\end{array}$ & SEM & $\begin{array}{l}\text { To understand how different } \\
\text { factors could impede or } \\
\text { enhance young consumer } \\
\text { purchase intention and } \\
\text { consumer attitude in organic } \\
\text { food context }\end{array}$ \\
\hline
\end{tabular}


(Konuk, 2018) NA

(Ham et al., 2018)

(Husic-

Mehmedovic

et al., 2017)

(Khare \&

Pandey, 2017)

(Singh \&

Verma, 2017)

(Mainardes et al., 2017)

NA
Price fairness, trust in organic food, organic food satisfaction

$349 ; 26-40 ; 57 \%$;

SEM Turkey

Means-end theory and Self-concept theory

\section{NA}

Schwartz's personal values
ATT, SN, PBC, uniqueness seeking the lifestyle

Perceived price, HC, knowledge of organic food, SN, availability

$\mathrm{HC}$, life equilibrium, perceived intrinsic FQA, perceived extrinsic FQA

Trust in retailer and WOM

$411 ; 30$

60(42.03); 75.2\%;

Croatia

$1000 ; 19-67$

(30.75); 63.8\%;

NM

541; NM; 47\%; India

$611 ; 36-55 ; 46 \%$; India

Values, ATT
Study $1-385 ; 30-$ 40; 62\%; Brazil Study2- 270; 3049; 68.5\%; Brazil
SEM

To study the relationship among identified constructs (price, satisfaction, trust and purchase intention)

To understand drivers of organic food purchasing

To examine the role of life equilibrium on purchase intention through food quality attribute (extrinsic and intrinsic)

To explore the relationship between retailer trust and WOM on purchase intention towards organic food

To understand the buying

factor

analysis,

ANOVA

independent

t-test, MLR,

MRA

SEM

To understand whether ATT acts as a mediator between values and purchase intention in emerging market 
(Chang \&

Chang, 2017)

NA

WOM effects and conformity

behaviours

(Persaud \& NA

Schillo, 2017)

(Yadav, 2016) NA

(Anisimova, 2016)

(Teng \& Lu, 2016)

(Lee, 2016)

NA

NA

(Hwang,

2016) perceived value, CI (altruistic values)

Healthism, hedonism, trust uncertainty

Self-presentation, EC, ethical identity, FS, income
431; NM; NM;

SEM

Taiwan

988; NM; 49.4\%; SEM

Social identity, social influence,

Health concern (egoistic value), EC

Organic food motives (HC,FS, ecological motives), involvement,

Canada

304; 18-30; 48\%; SEM

India

1011; NM; NM;

Australia

MRA

457; 40-59;

$67.8 \%$; Taiwan

SEM

$898 ; 45.6 ; 54.5 \% ; \quad$ SEM

Number of children, the age of children and perceived convenience

\section{US}

Sample 1-183; 48.44; 67.9\%; US Sample 2-153; 21.1; 59\%; US
To understand the association between WOM, interpersonal influence and purchase intention

How innovativeness affects the purchase decision

To study the effect of different values (altruistic \& egoistic) in measuring the purchase intention

To study the impact of healthism, hedonism and trust on purchase intention

To study the influence of consumption motives on intention through measuring involvement as mediator and uncertainty as moderator

To understand the influence of individual and situational factor on purchase intention

To study the motivation of older consumer purchase intention 
(Yadav \&

Pathak, 2016a)

(Lee and Yun 2015)

(Yazdanpanah \& Forouzani, 2015)

(Pandey \&

Khare, 2015)

(Dowd \&

Burke, 2013)

(Zagata, 2012)
ATT, PBC, SN, moral attitude, EC, $\mathrm{HC}$

$220 ; 18-30 ; 45 \% ; \quad$ SEM India

Utilitarian attitude, hedonic attitude $\quad 725 ; ; 20-85 ; 55 \% ; \quad$ SEM US

Organism-

Response

Model (S-O-R)

TPB

Environmental Cosmopolitan, environment, opinion

value-attitude- leadership, opinion seeking system model

ATT, PBC, SN, moral norm, selfidentity

$389 ; 18-32$

(20.98); 64.3\%;

Iran

$541 ; 18-30 ; 47 \%$.

India

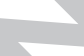

ATT, SN, PBC and intention, moral ATT and ethical identity, FCM

$137 ; 19-$

80(40.37), 80\%; $\mathrm{NM}$

1054; Czech Republic
To identify factors affecting purchase intention towards organic food

To investigate attribute that affects consumer purchase intention

To identify motivating factors for consuming organic food

To understand the impact of cosmopolitan and environment on intention and also measuring the mediating position of opinion leadership and opinion seeking

MRA

To examine the three steps adaption of the TPB to measure intention of consumers buying sustainably sourced food

ANOVA, Correlation
To explain consumer decision process during organic food purchases 
(Chen and
Lobo 2012)

Product, regulatory, lifestyle, ethnocentric, attitude, post purchase evaluation

FS, HC, ethical identity, attitude

$\&$ Guido,

2012)

(Dean, Raats, \& Shepherd, 2012)

(Smith \& Paladino, 2010)

(Michaelidou

NA \& Hassan, 2010)

NA

TPB

B

$1160 ; 18-60$

SEM $60 \%$; China

291; 47.04; NM;
Italy

SEM 


\begin{tabular}{|c|c|c|c|c|c|}
\hline $\begin{array}{l}\text { (Lodorfos \& } \\
\text { Dennis, 2008) }\end{array}$ & ТPB & ATT, SN, PBC, demographic & $\begin{array}{l}\text { 144; 18-44; NM; } \\
\text { UK }\end{array}$ & $\begin{array}{l}\text { Correlation, } \\
\text { T-test, MRA }\end{array}$ & $\begin{array}{l}\text { To examine the determinants } \\
\text { influencing purchase intention } \\
\text { towards organic food }\end{array}$ \\
\hline $\begin{array}{l}\text { (Arvola et al., } \\
\text { 2008) }\end{array}$ & TPB & SN, belief, moral norm, ATT & $\begin{array}{l}672 ; 18-65 ; \mathrm{NM} \\
\text { Italy, Finland \& } \\
\text { UK }\end{array}$ & SEM & $\begin{array}{l}\text { To examine the role of } \\
\text { effective and moral attitude on } \\
\text { consumer intention }\end{array}$ \\
\hline $\begin{array}{l}\text { (Michaelidou } \\
\text { \& Hassan, } \\
\text { 2008) }\end{array}$ & NA & HC, FS and ethical-self-identity, ATT & $\begin{array}{l}222 ; 15-65 ; 72 \% \\
\text { Scotland }\end{array}$ & & $\begin{array}{l}\text { To study the role of HC, FS } \\
\text { and ethical-self-identity in } \\
\text { determining intention of } \\
\text { consumers }\end{array}$ \\
\hline
\end{tabular}

*(Total size, age range, gender distribution $(\mathbf{F})$, country)

Abbreviations: NM-not mentioned; NA-not applicable; SEM-Structural equation modelling; TPB-Theory of planned behaviour; MRA-

Multiple regression analysis; MLR-Multiple linear regression; WOM-word of mouth; WTP- willingness to pay, ATT-Attitude, SN-subjective norm, PBC-perceived behavioural control, HC-health consciousness, EC-environmental concern, CI- consumer innovativeness, FS-food safety, FQA-food quality attributes, CDP-consumer decision making process, HOEM-hierarchy of effect model, FCM-food choice motives 
Table 2. Demographic profile of the study participants

\begin{tabular}{llc}
\hline Study variables & Category & Frequency (percentage \%) \\
\hline Gender & Male & $314(69)$ \\
Age & Female & $138(31)$ \\
& 60 Years and Above & $7(2)$ \\
& $50-59$ & $24(5)$ \\
& $40-49$ & $31(7)$ \\
& $30-39$ & $138(31)$ \\
Education & 29 and below & $253(57)$ \\
& PhD & $34(8)$ \\
& Postgraduate & $191(42)$ \\
& Graduate & $148(33)$ \\
Occupation & Undergraduate & $80(18)$ \\
& Business & $79(17)$ \\
Household Income & Service & $223(49)$ \\
How often do you buy organic food product & Student & $151(33)$ \\
& Once in a wakh and Above & $13(3)$ \\
& Many times in a week & $5(1)$ \\
& Once in a month & $30(7)$ \\
& Many times in a year & $117(26)$ \\
& Never & $287(63)$ \\
& No-29 Lakh & $283(62)$ \\
& $10-19$ Lakh & $170(38)$ \\
& Below 10 Lakh & $90(20)$ \\
& Yes & $71(16)$ \\
& No & $22(5)$ \\
& & $100(22)$ \\
& & $170(38)$ \\
\hline
\end{tabular}


Table 3. Study measures, measurement items, and factor loadings for measurement and structural models

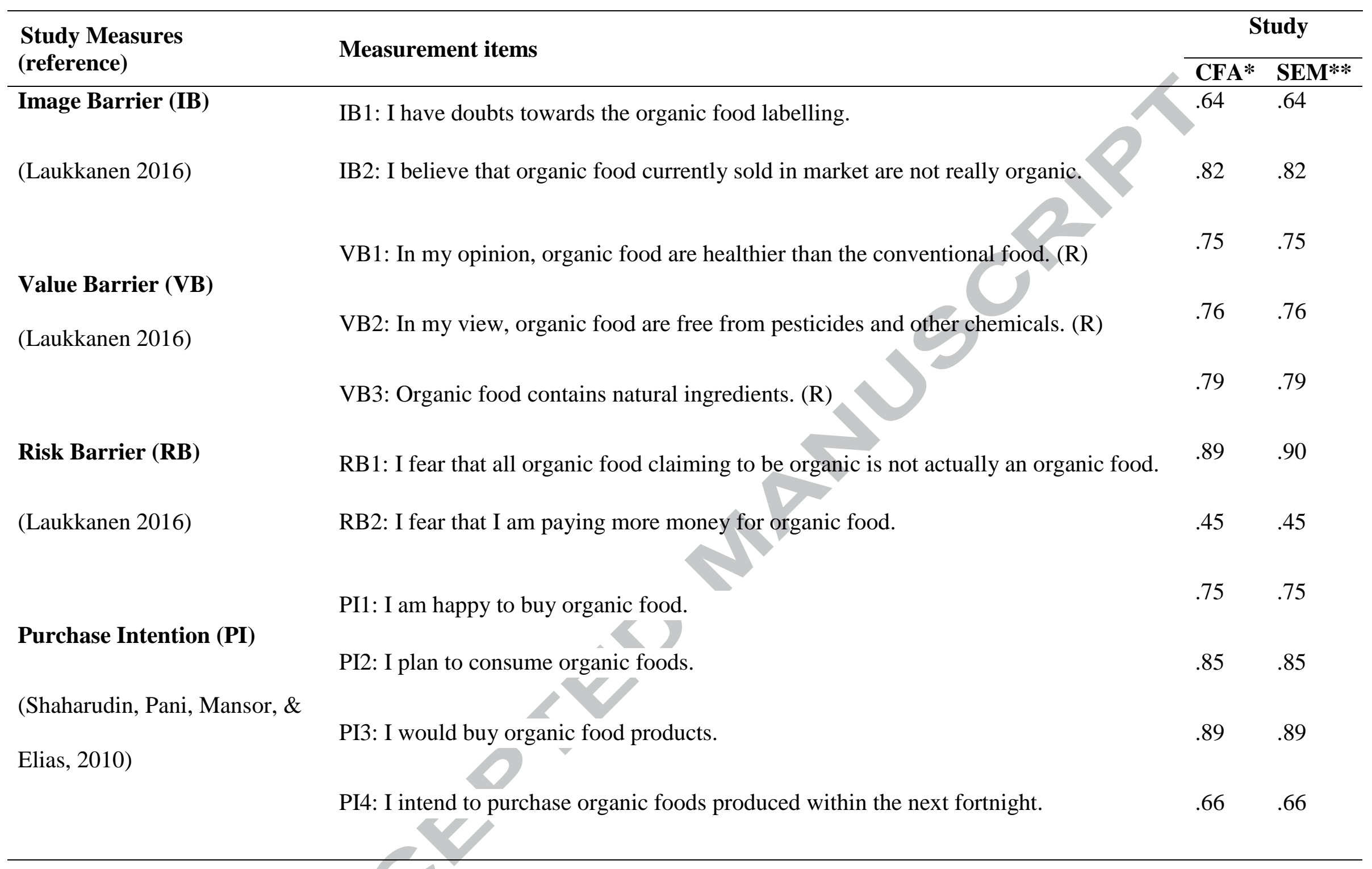




\begin{tabular}{|c|c|c|c|}
\hline Ethical Consumption & ECI1: I intend to consume ethical products. & .88 & .88 \\
\hline Intention (ECI) & ECI2: I plan to consume ethical products. & .92 & .92 \\
\hline (Huh, 2011; Shaw \& Shiu, & ECI3: I prefer ethical products to other products. & \multicolumn{2}{|c|}{ 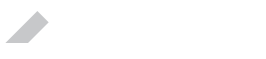 } \\
\hline \multirow[t]{2}{*}{ 2002) } & & & J. \\
\hline & $\begin{array}{l}\text { CB 1: I make a special effort to buy paper and plastic products that are made from } \\
\text { recycled materials. }\end{array}$ & .71 & .71 \\
\hline Choice Behavior (CB) & CB2: I have switched products for ecological reasons. & .79 & .79 \\
\hline (Lin \& Huang, 2012; Roberts, & $\begin{array}{l}\text { CB3: When I have a choice between two equal products, I purchase the one less } \\
\text { harmful to other people and the environment. }\end{array}$ & .71 & .71 \\
\hline 1996) & $\begin{array}{l}\text { CB4: I make a special effort to buy household chemicals such as detergents and } \\
\text { cleansing solutions that are environmentally friendly. }\end{array}$ & .70 & .70 \\
\hline
\end{tabular}

$\mathrm{CFA}^{*}$ = factor loadings for measurement model, SEM** factor loadings for structural model 
Table 4. Validity and reliability analysis

\begin{tabular}{|c|c|c|c|c|c|c|c|c|c|c|}
\hline & CR & AVE & MSV & ASV & ECI & Image & Value & Risk & PI & CB \\
\hline ECI & .91 & .77 & .16 & .09 & .88 & & & & & \\
\hline IB & .70 & .55 & .28 & .06 & .12 & .74 & & & & \\
\hline VB & .81 & .58 & .37 & .13 & .33 & -.03 & & & & \\
\hline RB & .64 & .50 & .28 & .07 & .17 & 5 & .12 & .71 & & \\
\hline PI & .87 & .63 & .37 & .16 & .41 & & .61 & .07 & .79 & \\
\hline CB & .82 & .53 & .25 & .11 & .38 & 03 & .38 & .02 & .50 & .73 \\
\hline
\end{tabular}

Ethical Consumption Intention (ECI), Image Barrier (IB), Value Barrier (VB), Risk Barrier (RB), Purchase Intention (PI), Choice Behavior (CB), Composite Reliability (CR), Average Shared Variance (ASV), Maximum Shared Variance (MSV), Average Variance Extracted (AVE) 
Table 5: Moderation Results for Buyer/Non-Buyer

\begin{tabular}{ccccccc}
\hline & $\boldsymbol{\beta}$ & $\boldsymbol{t}$ & $\boldsymbol{p}$ & $\boldsymbol{L L C I}$ & $\boldsymbol{U L C I}$ & Moderation? \\
\hline $\mathbf{I B} \rightarrow \mathbf{P I}$ & .06 & .77 & .44 & -.0980 & .2235 & No \\
$\mathbf{V B} \rightarrow \mathbf{P I}$ & .16 & 1.86 & .06 & -.0093 & .3272 & Yes \\
$\mathbf{R B} \rightarrow \mathbf{P I}$ & -.08 & -.77 & .44 & -.2698 & .1178 & No \\
$\mathbf{I B} \rightarrow \mathbf{E C I}$ & -.08 & -.87 & .39 & -.2458 & .0953 & No \\
$\mathbf{V B} \rightarrow \mathbf{E C I}$ & .19 & 1.90 & .06 & -.0060 & .3814 & Yes \\
$\mathbf{R B} \rightarrow \mathbf{E C I}$ & -.14 & -1.33 & .19 & -.3397 & .0660 & No \\
$\mathbf{I B} \rightarrow \mathbf{C B}$ & .02 & .22 & .82 & -.1408 & .1769 & No \\
$\mathbf{V B} \rightarrow \mathbf{C B}$ & .02 & .20 & .84 & -.1619 & .1983 & No \\
$\mathbf{R B} \rightarrow \mathbf{C B}$ & -.12 & -1.21 & .23 & -.3086 & .0734 & No \\
$\mathbf{E C I} \rightarrow \mathbf{P I}$ & .13 & 1.57 & .12 & -.0336 & .3027 & No \\
$\mathbf{E C I} \rightarrow \mathbf{C B}$ & -.10 & -1.18 & .24 & -.2696 & .0674 & No \\
$\mathbf{P I} \rightarrow \mathbf{C B}$ & .06 & .74 & .46 & -.1060 & .2335 & No \\
\hline
\end{tabular}

Note: $\mathrm{LLCI}=$ Lower limit of confidence interval, ULCI $=$ Upper limit of confidence interval, $\beta=$ standardized regression weight, $t=\mathrm{t}$ value 
Table 6: Moderation Analysis for Buyer/Non-Buyer

$\begin{array}{lllll}\text { Effect } & t & p & \text { LLCI } & \text { ULCI }\end{array}$

\begin{tabular}{ccccc}
\hline VB $\rightarrow$ PI & & & & \\
\hline Buyer & .54 & 8.90 & .000 & .4217 \\
Non-Buyer & .38 & 6.35 & .000 & .2639 \\
\hline VB $\rightarrow$ ECI & & & & .6608 \\
\hline Buyer & .39 & 5.51 & .000 & .2480 \\
Non-Buyer & .20 & 2.85 & .004 & .0616 \\
\end{tabular}


Table 7: Moderation Results for Environmental Concern

\begin{tabular}{|c|c|c|c|c|c|c|}
\hline & $\beta$ & $t$ & $p$ & $L L C I$ & ULCI & Moderation? \\
\hline IB $\rightarrow$ PI & .05 & 1.22 & .22 & -.0305 & .1310 & No \\
\hline $\mathrm{VB} \rightarrow \mathrm{PI}$ & .11 & 2.62 & .01 & .0279 & .1957 & Yes \\
\hline $\mathbf{R B} \rightarrow \mathbf{P I}$ & -.01 & -.30 & .76 & -.1075 & .0787 & No \\
\hline $\mathrm{IB} \rightarrow \mathrm{ECI}$ & -.06 & -1.40 & .16 & -.1395 & .0235 & No \\
\hline $\mathrm{VB} \rightarrow \mathrm{ECI}$ & -.04 & -.85 & .40 & -.1327 & .0527 & No \\
\hline $\mathrm{RB} \rightarrow \mathrm{ECI}$ & -.07 & -1.58 & .11 & 2 & .0180 & No \\
\hline $\mathrm{IB} \rightarrow \mathrm{CB}$ & .08 & 2.25 & .03 & .0102 & .1511 & Yes \\
\hline $\mathrm{VB} \rightarrow \mathrm{CB}$ & .05 & .99 & .32 & -.0399 & .1212 & No \\
\hline $\mathrm{RB} \rightarrow \mathrm{CB}$ & .04 & 1.07 & .29 & -.0371 & .1257 & No \\
\hline $\mathrm{ECI} \rightarrow \mathrm{PI}$ & .02 & .44 & .66 & -.0701 & .1103 & No \\
\hline $\mathrm{ECI} \rightarrow \mathrm{CB}$ & -.04 & -.95 & .34 & -.1192 & .0417 & No \\
\hline $\mathrm{PI} \rightarrow \mathrm{CB}$ & -.06 & -1.6 & .11 & -.1391 & .0135 & No \\
\hline
\end{tabular}


Table 8: Moderation Analysis for Environmental Concern

\begin{tabular}{|c|c|c|c|c|c|}
\hline & Effect & $t$ & $p$ & $L L C I$ & $U L C I$ \\
\hline \multicolumn{6}{|l|}{$\mathrm{VB} \rightarrow \mathrm{PI}$} \\
\hline Low & .39 & 6.98 & .000 & .2787 & .4971 \\
\hline Medium & .50 & 10.94 & .000 & & .5895 \\
\hline High & .61 & 8.89 & .000 & .4763 & .7467 \\
\hline \multicolumn{6}{|l|}{$\mathrm{IB} \rightarrow \mathrm{CB}$} \\
\hline Low & -.08 & -1.71 & 99 & -.1768 & .0124 \\
\hline Medium & -.002 & -.042 & 1 & -.0743 & .0712 \\
\hline High & .08 & 1.44 & .15 & -.0285 & .1866 \\
\hline
\end{tabular}




\section{Highlights}

- Investigates consumer resistance toward the consumption of organic food

- Popular theory on consumer resistance, namely, innovation resistance, was utilized

- Value is a significant barrier to ethical consumption intention and purchase intention

- Ethical consumption has a positive association to purchase intention and choice behavior

- Moderating influence of buying involvement on barriers and decisions proved insignificant

- Moderating influence of environmental concern on barriers and decisions proved insignificant 